This PDF is a selection from a published volume from the National Bureau of Economic Research

Volume Title: International Dimensions of Monetary Policy

Volume Author/Editor: Jordi Gali and Mark J. Gertler, editors

Volume Publisher: University of Chicago Press

Volume ISBN: 0-226-27886-7

Volume URL: http://www.nber.org/books/gert07-1

Conference Date: June 11-13, 2007

Publication Date: February 2010

Chapter Title: Monetary Rules in Emerging Economies with Financial Market Imperfections

Chapter Author: Nicoletta Batini, Paul Levine, Joseph Pearlman

Chapter URL: http://www.nber.org/chapters/c0519

Chapter pages in book: $(251-311)$ 


\title{
Monetary Rules in Emerging Economies with Financial Market Imperfections
}

\author{
Nicoletta Batini, Paul Levine, and Joseph Pearlman
}

\subsection{Introduction}

Over the past twenty years there has been a marked shift toward more flexible exchange rate regimes and more open capital accounts by both industrial and emerging market countries. Exchange rate targets accounted for over half of monetary policy regimes in 1985, but declined to just 5 percent in 2005, while in emerging market and other developing countries the share fell from 75 percent to 55 percent.

The move to more flexible exchange rate regimes has been accompanied by a variety of frameworks to conduct monetary policy, including inflation targeting, monetary targeting, and more eclectic approaches involving multiple objectives. In industrial countries, exchange rate pegs and monetary targets have been replaced by eclectic regimes in G-3 countries, and by direct inflation targets almost everywhere else. In emerging market countries exchange rate pegs were replaced mainly by money targets through the mid1990s. Since then, however, money targets as well as exchange rate pegs have been replaced by direct inflation targets.

Over the next few years, the trend toward adoption of flexible exchange

Nicoletta Batini is a Senior Economist at the IMF and a professor of economics at the University of Surrey. Paul Levine is a professor of economics at the University of Surrey. Joseph Pearlman is a professor of economics at London Metropolitan University.

Paper presented to the NBER conference on International Dimensions of Monetary Policy, S'Agaro, Catalonia, Spain, June 11-13, 2007. The chapter has benefited from comments of participants, particularly those of our discussant, Frederic Mishkin, and the conference organizers, Jordi Galí and Mark Gertler. We acknowledge financial support for this research from the ESRC, project no. RES-000-23-1126. We also acknowledge the Research Visitors Programme of the Central Reserve Bank of Peru for Paul Levine. Thanks are owed to the Central Bank of Peru for their hospitality and to Paul Castillo, Carlos Montoro, and Vicente Tuesta, in particular, for stimulating discussions. 
rate regimes, and inflation targeting in particular, is expected to continue. A recent International Monetary Fund (IMF) survey of eighty-eight nonindustrial countries found that more than half expressed a desire to move to explicit or implicit quantitative inflation targets. Moreover, nearly threequarters of these countries envisage a shift to full-fledged inflation targeting by 2010 (Batini, Breuer, and Kochhar 2006).

While there are undoubtedly countries where inflation targeting may not be a suitable framework, it is a flexible framework that can be adapted to particular needs of nonindustrial countries. Nonindustrial country inflation targeters face a number of challenges that differ in character or in degree from those faced in industrial economies. Calvo and Mishkin (2003) highlight five particularly important challenges for emerging market countries. These include: (a) weak public sector financial management; (b) weak financial sector institutions and markets; (c) low monetary policy credibility; (d) extensive dollarization of financial liabilities; and (e) vulnerability to sharp changes in capital flows and international investor sentiment. In addition, many of these countries face considerably greater uncertainty about the structure of their economies, the monetary policy transmission mechanism, and the cyclical position of the economy than is typical of industrial country inflation targeters.

Our goal in this chapter is to understand whether, for nonindustrial countries facing such challenges, inflation targets are better or worse than (fix or soft) exchange rate targets. In particular we try to answer two central questions:

1. How do financial frictions in emerging markets affect the transmission mechanism of monetary policy and the volatility of the economy?

2. Can and should central banks in emerging markets facing financial frictions and vulnerable to combination of internal and external shocks try to balance inflation and exchange rate stabilization objectives?

We address these questions by developing a two-bloc emerging market, a rest of the world dynamic stochastic general equilibrium (DSGE) model where, in the emerging market bloc there is a strong link between changes in the exchange rate and financial distress of household and firms. More precisely, we assume that: (a) there are financial frictions in the form of a "financial accelerator," since firms are obliged to finance at least part of their capital requirements in foreign currency (see Gertler, Gilchrist, and Natalucci [2003] and Gilchrist [2003]); (b) domestic households hold both local and foreign currency money balances for transaction purposes; and (c) the relative demand of foreign currency is endogenous to the extent of exchange rate stabilization by the central bank. The simultaneous assumption of (a) through (c) is novel in the literature.

We shock the model to understand how such financial frailties affect monetary transmission and inflation output trade-offs in the emerging market 
bloc. Using welfare analysis, we then compare the performance of monetary policy rules with different degrees of exchange rate flexibility and identify the rule for the emerging market central bank that responds to a combination of internal and external shocks at the smallest welfare cost.

The rest of the chapter is organized as follows. Section 5.2 presents the model. Section 5.3 sets out the form of monetary rules under investigation. In section 5.4 we study an analytically tractable form of the model without capital. The focus here is on the effects of transactions dollarization. In section 5.5 we explore the workings of the model and the monetary transmission mechanism in particular; we examine, under optimal policy, the volatility of key economic variables in the domestic economy and impulse response functions to a technology shock and to the country's borrowing premium shock. In section 5.6 we derive and compare alternative monetary policy rules that encompass various degrees of exchange rate flexibility, with, at one extreme, inflation targeting under a pure float, and at the other extreme, fixed exchange rates. Both domestic and consumer price inflation targets are examined. Section 5.7 addresses the requirement that monetary rules should be operational in the sense that, in the face of shocks, the zero lower bound constraint on the nominal interest rate is very rarely hit. Section 5.8 provides concluding remarks.

\subsection{The Model}

We start from a standard two-bloc microfounded model along the lines of Obstfeld and Rogoff (1995) to then incorporate many of the nominal and real frictions that have been shown to be empirically important in the study of closed economies (e.g., Smets and Wouters 2003). The blocs are asymmetric and unequally sized, each one with different household preferences and technologies. The single small open economy then emerges as the limit when the relative size of the larger bloc tends to infinity. Households work, save, and consume tradable goods produced both at home and abroad. At home there are three types of firms: wholesale, retail, and capital producers. As in Gertler et al. (2003), wholesale firms borrow from households to buy capital used in production and capital producers build new capital in response to the demand of wholesalers. Wholesalers' demand for capital in turn depends on their financial position which varies inversely with wholesalers' net worth.

There are four departures from the standard open economy model that lead to interesting results. First, money enters utility in a nonseparable way and results in a direct impact of the interest rate on the supply side. ${ }^{1}$ Second, in the emerging market bloc, households derive utility from holding both domestic and foreign money (dollars) balances as in Felices and Tuesta

1. See Woodford (2003, chapter 4). A “cost channel," as in Ravenna and Walsh (2006), has a similar supply-side effect on the Phillips curve. 
(2006). Third, along the lines of Gilchrist (2003) (see also Cespedes, Chang, and Velasco [2004]), firms face an external finance premium that increases with leverage and part of the debt of wholesale firms is financed in foreign currency (dollars), because it is impossible for firms to borrow 100 percent in domestic currency owing to "original sin"-type constraints. Finally, there are frictions in the world financial markets facing households as in Benigno (2001). Departures two and three add an additional dimension to openness itself, namely one whereby domestic agents not only hold foreign bonds and derive utility from consuming foreign produced goods, as in standard open economy models, but also borrow in foreign currency from domestic agents and derive utility from holding foreign money balances. Details of the model are as follows.

\subsubsection{Households}

Normalizing the total population to be unity, there are $v$ households in the "home," emerging economy bloc and $(1-v)$ households in the "foreign" bloc. A representative household $h$ in the home bloc maximizes

$$
E_{t} \sum_{t=0}^{\infty} \beta^{t} U\left(C_{t}(h), \frac{M_{H, t}(h)}{P_{t}}, \frac{M_{F, t}(h) S_{t}}{P_{t}}, L_{t}(h), \varepsilon_{C, t}, \varepsilon_{M_{\mathrm{H}}, t}, \varepsilon_{M_{\mathrm{F}}, t}, \varepsilon_{L, t}\right),
$$

where $E_{t}$ is the expectations operator indicating expectations formed at time $t, \beta$ is the household's discount factor, $C_{t}(h)$ is a Dixit-Stiglitz index of consumption defined following in equation (5), $M_{H, t}(h)$ and $M_{F, t}(h)$ are end-of-period nominal domestic and foreign currency balances, respectively, $P_{t}$ is a Dixit-Stiglitz price index defined in equation (11), $S_{t}$ is the nominal exchange rate, and $L_{t}(h)$ are hours worked. A preference shock to the marginal utility of consumption is $\varepsilon_{C, t}$, and $\varepsilon_{M_{\mathrm{H}}, t}, \varepsilon_{M_{\mathrm{F}}, t}$, and $\varepsilon_{L, t}$ are shocks to demand for domestic currency, demand for foreign currency, and labor supply, respectively. An analogous symmetric intertemporal utility is defined for the foreign representative household and the corresponding variables (such as consumption) are denoted by $C_{t}^{*}(h)$, and so forth.

We incorporate financial frictions facing households as in Benigno (2001). There are two risk free one-period bonds denominated in the currencies of each bloc with payments in period $t, B_{H, t}$, and $B_{F, t}$, respectively, in (per capita) aggregate. The prices of these bonds are given by

$$
P_{B, t}=\frac{1}{1+R_{n, t}} ; P_{B, t}^{*}=\frac{1}{\left(1+R_{n, t}^{*}\right) \phi\left(S_{t} B_{F, t} / P_{t}\right)},
$$

where $\phi(\cdot)$ captures the cost in the form of a risk premium for home households to hold foreign bonds. We assume $\phi(0)=0$ and $\phi^{\prime}<0$. The nominal interest rate over the interval $[t, t+1]$ are denoted by $R_{n, t}$ and $R_{n, t}^{*}$. For analytical convenience, the home households can hold foreign bonds, but foreign households cannot hold home bonds. Then the net and gross foreign 
assets in the home bloc are equal. The representative household $h$ must obey a budget constraint:

$$
\begin{aligned}
& P_{t} C_{t}(h)+P_{B, t} B_{H, t}(h)+P_{B, t}^{*} S_{t} B_{F, t}(h)+M_{H, t}(h)+S_{t} M_{F, t}(h) T F_{t}= \\
& W_{t}(h) L_{t}(h)+B_{H, t-1}(h)+S_{t} B_{F, t-1}(h)+M_{H, t-1}(h)+S_{t} M_{F, t-1}(h)+\Gamma_{t}(h),
\end{aligned}
$$

where $W_{t}(h)$ is the wage rate and $\Gamma_{t}(h)$ are dividends from ownership of firms. In addition, if we assume that households' labor supply is differentiated with elasticity of supply $\eta$, then (as we shall see following) the demand for each consumer's labor supplied by $v$ identical households is given by

$$
L_{t}(h)=\left(\frac{W_{t}(h)}{W_{t}}\right)^{-\eta} L_{t}
$$

where $W_{t}=\left[1 / \nu \sum_{r=1}^{v} W_{t}(h)^{1-\eta}\right]^{1 /(1-\eta)}$ and $L_{t}=\left[(1 / v) \sum_{r=1}^{v} L_{t}(h)^{(\eta-1) / \eta \eta}\right]^{\eta /(\eta-1)}$ are the average wage index and average employment, respectively.

Let the number of differentiated goods produced in the home and foreign blocs be $n$ and $(1-n)$, respectively, again normalizing the total number of goods in the world at unity. We also assume that the ratio of households to firms are the same in each bloc. It follows that $n$ and $(1-n)$ (or $v$ and $[1-v])$ are measures of size. The per capita consumption index in the home bloc is given by

$$
C_{t}(h)=\left[\mathrm{w}^{1 / \mu} C_{H, t}(h)^{(\mu-1) / \mu}+(1-\mathrm{w})^{1 / \mu} C_{F, t}(h)^{(\mu-1) / \mu}\right]^{\mu /(\mu-1)}
$$

where $\mu$ is the elasticity of substitution between home and foreign goods,

$$
\begin{aligned}
& C_{H, t}(h)=\left[\left(\frac{1}{n}\right)^{1 / \zeta} \sum_{f=1}^{n} C_{H, t}(f, h)^{(\zeta-1) / \zeta}\right]^{\zeta /(\zeta-1)} \\
& C_{F, t}(h)=\left[\left(\frac{1}{1-n}\right)^{1 / \zeta}\left(\sum_{f=1}^{1-n} C_{F, t}(f, h)^{(\zeta-1) / \zeta}\right)\right]^{\zeta /(\zeta-1)},
\end{aligned}
$$

where $C_{H, t}(f, h)$ and $C_{F, t}(f, h)$ denote the home consumption of household $h$ of variety $f$ produced in blocs $H$ and $F$, respectively, and $\zeta>1$ is the elasticity of substitution between varieties in each bloc. Analogous expressions hold for the foreign bloc, which are indicated with a superscript "*," and we impose $\zeta=\zeta^{*}$ for reasons that become apparent in the section on retail firms. ${ }^{2}$ Weights in the consumption baskets in the two blocs are defined by

$$
\mathrm{w}=1-(1-n)(1-\omega) ; \mathrm{w}^{*}=1-n\left(1-\omega^{*}\right) .
$$

2. Consistently we adopt a notation where subscript $H$ or $F$ refers to goods $H$ or $F$ produced in the home and foreign bloc, respectively. The presence (for the foreign bloc) or the absence (for the home bloc) of a superscript "*" indicates where the good is consumed or used as an input. Thus, $C_{H, t}^{*}$ refers to the consumption of the home good by households in the foreign bloc. Parameter $\omega$ and $\omega^{*}$ refer to the home and foreign bloc, respectively, and so forth. 
In equation $(6), \omega, \omega^{*} \in[0,1]$ are parameters that capture the degree of bias in the two blocs. If $\omega=\omega^{*}=1$, we have autarky, while $\omega=\omega^{*}=0$ gives us the case of perfect integration. In the limit, as the home country becomes small, $n \rightarrow 0$ and $v \rightarrow 0$. Hence, $\mathrm{w} \rightarrow \omega$ and $\mathrm{w}^{*} \rightarrow 1$. Thus the foreign bloc becomes closed, but as long as there is a degree of home bias and $\omega>0$, the home bloc continues to consume foreign produced consumption goods.

Denote by $P_{H, t}(f), P_{F, t}(f)$ the prices in domestic currency of the good produced by firm $f$ in the relevant bloc. Then the optimal intratemporal decisions are given by standard results:

$$
\begin{gathered}
C_{H, t}(r, f)=\left(\frac{P_{H, t}(f)}{P_{H, t}}\right)^{-\zeta} C_{H, t}(h) ; \quad C_{F, t}(r, f)=\left(\frac{P_{F, t}(f)}{P_{F, t}}\right)^{-\zeta} C_{F, t}(h) \\
C_{H, t}(h)=\mathrm{w}\left(\frac{P_{H, t}}{P_{t}}\right)^{-\mu} C_{t}(h) ; \quad C_{F, t}(h)=(1-\mathrm{w})\left(\frac{P_{F, t}}{P_{t}}\right)^{-\mu} C_{t}(h),
\end{gathered}
$$

where aggregate price indexes for domestic and foreign consumption bundles are given by

$$
\begin{aligned}
P_{H, t} & =\left[\frac{1}{n} \sum_{f=1}^{n} P_{H, t}(f)^{1-\zeta}\right]^{1 /(1-\zeta)} \\
P_{F, t} & =\left[\frac{1}{1-n} \sum_{f=1}^{1-n} P_{F, t}(f)^{1-\zeta}\right]^{1 /(1-\zeta)},
\end{aligned}
$$

and the domestic consumer price index $P_{t}$ given by

$$
P_{t}=\left[\mathrm{w}\left(P_{H, t}\right)^{1-\mu}+(1-\mathrm{w})\left(P_{F, t}\right)^{1-\mu}\right]^{1 /(1-\mu)},
$$

with a similar definition for the foreign bloc.

Let $S_{t}$ be the nominal exchange rate. The law of one price applies to differentiated goods so that $S_{t} P_{F, t}^{*} / P_{F, t}=S_{t} P_{H, t}^{*} / P_{H, t}=1$. Then it follows that the real exchange rate $R E R_{t}=S_{t} P_{t}^{k} / P_{t}$ and the terms of trade, defined as the domestic currency relative price of imports to exports $\mathcal{T}_{t}=P_{F, t} / P_{H, t}$, are related by the relationship

$$
R E R_{t} \equiv \frac{S_{t} P_{t}^{*}}{P_{t}}=\frac{\left[\mathrm{w}^{*}+\left(1-\mathrm{w}^{*}\right) \mathcal{T}_{t}^{\mu *-1}\right]^{1 /\left(1-\mu^{*}\right)}}{\left[1-\mathrm{w}+\mathrm{w} \mathcal{T}_{t}^{\mu-1}\right]^{1 /(1-\mu)}}
$$

Thus if $\mu=\mu^{*}$, then $R E R_{t}=1$ and the law of one price applies to the aggregate price indexes if $\mathrm{w}^{*}=1-\mathrm{w}$. The latter condition holds if there is no home bias. If there is home bias, the real exchange rate appreciates $\left(R E R_{t}\right.$ falls) as the terms of trade deteriorates.

We assume flexible wages. Then maximizing equation (1) subject to equations (3) and (4), treating habit as exogenous, and imposing symmetry on households (so that $C_{t}(h)=C_{t}$, etc.) yields standard results: 


$$
\begin{aligned}
P_{B, t} & =\beta E_{t}\left[\frac{U_{C, t+1}}{U_{C, t}} \frac{P_{t}}{P_{t+1}}\right] \\
U_{M_{H}, t} & =U_{C, t}\left[\frac{R_{n, t}}{1+R_{n, t}}\right] \\
U_{M_{F}, t} & =U_{C, t}\left[\frac{R_{n, t}^{*}}{1+R_{n, t}^{*}}\right] \\
\frac{W_{t}}{P_{t}} & =-\frac{\eta}{(\eta-1)} \frac{U_{L, t}}{U_{C, t}},
\end{aligned}
$$

where $U_{C, t}, U_{M_{\mathrm{H}, t},}, U_{M_{\mathrm{F}}, t}$, and $-U_{L, t}$ are the marginal utility of consumption, money holdings in the two currencies, and the marginal disutility of work, respectively. Taking expectations of (13), the familiar Keynes-Ramsey rule, and its foreign counterpart, we arrive at the modified UIP condition

$$
\frac{P_{B, t}}{P_{B, t}^{*}}=\frac{E_{t}\left[U_{C, t+1}\left(P_{t} / P_{t+1}\right)\right]}{E_{t}\left[U_{C, t+1}\left(S_{t+1} P_{t} / S_{t} P_{t+1}\right)\right]} \text {. }
$$

In (14), the demand for money balances depends positively on the marginal utility of consumption and negatively on the nominal interest rate. If, as is common in the literature, one adopts a utility function that is separable in money holdings, then given the central bank's setting of the latter and ignoring seignorage in the government budget constraint money demand is completely recursive to the rest of the system describing our macromodel. However, separable utility functions are implausible (see Woodford [2003], chapter 3, section 3.4) and following Felices and Tuesta (2006) we will not go down this route. Finally, in (16) the real disposable wage is proportional to the marginal rate of substitution between consumption and leisure, $-U_{L, t} / U_{C, t}$, and the constant of proportionality reflects the market power of households that arises from their monopolistic supply of a differentiated factor input with elasticity $\eta$.

\subsubsection{Firms}

There are three types of firms: wholesale, retail, and capital producers. Wholesale firms are run by risk-neutral entrepreneurs who purchase capital and employ household labor to produce a wholesale good that is sold to the retail sector. The wholesale sector is competitive, but the retail sector is monopolistically competitive. Retail firms differentiate the wholesale goods at no resource cost and sell the differentiated (repackaged) goods to households. The capital goods sector is competitive and converts the final goods into capital. The details are as follows. 


\section{Wholesale Firms}

Wholesale goods are homogeneous and produced by entrepreneurs who combine differentiated labor and capital with a technology

$$
Y_{t}^{W}=A_{t} K_{t}^{\alpha} L_{t}^{1-\alpha},
$$

where $K_{t}$ is beginning-of-period $t$ capital stock,

$$
L_{t}=\left[\left(\frac{1}{v}\right)^{1 / \eta} \sum_{r=1}^{v} L_{t}(h)^{(\eta-1) / \eta}\right]^{\eta /(\eta-1)},
$$

where we recall that $L_{t}(h)$ is the labor input of type $h$, and $A_{t}$ is an exogenous shock capturing shifts to trend total factor productivity in this sector. ${ }^{3}$ Minimizing wage costs $\sum_{h=1}^{v} W_{t}(h) L_{t}(h)$ gives the demand for each household's labor as

$$
L_{t}(h)=\left(\frac{W_{t}(h)}{W_{t}}\right)^{-\eta} L_{t} .
$$

Wholesale goods sell at a price $P_{H, t}^{W}$ in the home bloc. Equating the marginal product and cost of aggregate labor gives

$$
W_{t}=P_{H, t}^{W}(1-\alpha) \frac{Y_{t}}{L_{t}}
$$

Let $Q_{t}$ be the real market price of capital in units of total household consumption. Then noting that profits per period are $P_{H, t}^{W} Y_{t}-W_{t} L_{t}=\alpha P_{H, t}^{W} Y_{t}$, using equation (21), the expected return on capital, acquired at the beginning of period $t$ over the period is given by

$$
E_{t}\left(1+R_{t}^{k}\right)=\frac{\left(P_{H, t}^{W} / P_{t}\right) \alpha\left(Y_{t} / K_{t}\right)+(1-\delta) E_{t}\left[Q_{t+1}\right]}{Q_{t}},
$$

where $\delta$ is the depreciation rate of capital. This expected return must be equated with the expected cost of funds over $[t, t+1]$, taking into account credit market frictions. Wholesale firms borrow in both home and foreign currency, with proportion of the former given by $\varphi \in[0,1]$, so that this expected cost is

$$
\begin{array}{r}
\left(1+\Theta_{t}\right) \varphi E_{t}\left[\left(1+R_{n, t}\right) \frac{P_{t}}{P_{t+1}}\right]+\left(1+\Theta_{t}\right)(1-\varphi) E_{t}\left[\left(1+R_{n, t}^{*}\right) \frac{P_{t}^{*}}{P_{t+1}^{*}} \frac{R E R_{t+1}}{R E R_{t}}\right] \\
=\left(1+\Theta_{t}\right)\left\{\varphi E_{t}\left[\left(1+R_{t}\right)\right]+(1-\varphi) E_{t}\left[\left(1+R_{t}^{*}\right) \frac{R E R_{t+1}}{R E R_{t}}\right]\right\} .
\end{array}
$$

3. Following Gilchrist, Hairault, and Kempf (2002) and Gilchrist (2003), we ignore the managerial input into the production process and later, consistent with this, we ignore the contribution of the managerial wage in her net worth. 
If $\varphi=1$ or if UIP holds, this becomes $\left(1+\Theta_{t}\right) E_{t}\left[1+R_{t}\right]$. In (23), $R E R_{t} \equiv$ $P_{t}^{*} S_{t} / P_{t}$ is the real exchange rate, $R_{t-1} \equiv\left[\left(1+R_{n, t-1}\right)\left(P_{t-1} / P_{t}\right)\right]-1$ is the ex post real interest rate over $[t-1, t]$ and $\Theta_{t} \geq 0$ is the external finance premium given by

$$
\Theta_{t}=\Theta\left(\frac{B_{t}}{N_{t}}\right) ; \Theta^{\prime}(\cdot)>0, \Theta(0)=0, \Theta(\infty)=\infty,
$$

where $B_{t}=Q_{t} K_{t}-N_{t}$ is bond-financed acquisition of capital in period $t$ and $N_{t}$ is the beginning-of-period $t$ entrepreneurial net worth, the equity of the firm. Note that the ex post return at the beginning of period $t, R_{t-1}^{k}$, is given by

$$
1+R_{t-1}^{k}=\frac{\left(P_{H, t-1}^{W} / P_{t-1}\right) \alpha\left(Y_{t-1} / K_{t-1}\right)+(1-\delta) Q_{t}}{Q_{t-1}},
$$

and this can deviate from the ex-ante return on capital.

Assuming that entrepreneurs exit with a given probability $1-\xi_{e}$, net worth accumulates according to

$$
N_{t}=\xi_{e} V_{t},
$$

where $V_{t}$ the net value carried over from the previous period is given by

$$
\begin{aligned}
V_{t}= & {\left[\left(1+R_{t-1}^{k}\right) Q_{t-1} K_{t-1}-\left(1+\Theta_{t-1}\right)\right.} \\
& \left.\cdot\left(\varphi\left(1+R_{t-1}\right)+(1-\varphi)\left(1+R_{t-1}^{*}\right) \frac{R E R_{t}}{R E R_{t-1}}\right)\left(Q_{t-1} K_{t-1}-N_{t-1}\right)\right] .
\end{aligned}
$$

Note that in (27), $\left(1+R_{t-1}^{k}\right)$ is the ex post return on capital acquired at the beginning of period $t-1,\left(1+R_{t-1}\right)$ is the ex post real cost of borrowing in home currency, and $\left(1+R_{t-1}^{*}\right) R E R_{t} / R E R_{t-1}$ is the ex post real cost of borrowing in foreign currency. Also note that net worth $N_{t}$ at the beginning of period $t$ is a nonpredetermined variable since the ex post return depends on the current market value $Q_{t}$, itself a nonpredetermined variable.

Exiting entrepreneurs consume $C_{t}^{e}$, the remaining resources, given by

$$
C_{t}^{e}=\left(1-\xi_{e}\right) V_{t},
$$

of which consumption of the domestic good, as in equation (8), is given by

$$
C_{H, t}^{e}=\mathrm{w}\left(\frac{P_{H, t}}{P_{t}}\right)^{-\mu} C_{t}^{e} .
$$

\section{Retail Firms}

Retail firms are monopolistically competitive, buying wholesale goods and differentiating the product at a fixed resource cost $F$. In a free-entry equilibrium profits are driven to zero. Retail output for firm $f$ is then $Y_{t}(f)$ $=Y_{t}^{W}(f)-F$ where $Y_{t}^{W}$ is produced according to production technology (18). 
Retail firms set prices of differentiated goods according to the following. Assume that there is a probability of $1-\xi_{H}$ at each period that the price of each good $f$ is set optimally to $\hat{P}_{H, t}(f)$. If the price is not reoptimized, then it is held constant. ${ }^{4}$ For each producer $f$ the objective at time $t$ is to choose $\hat{P}_{H, t}(f)$ to maximize discounted profits

$$
E_{t} \sum_{k=0}^{\infty} \xi_{H}^{k} D_{t, t+k} Y_{t+k}(f)\left[\hat{P}_{H, t}(f)-P_{H, t+k} M C_{t+k}\right],
$$

where $D_{t, t+k}$ is the discount factor over the interval $[t, t+k]$, subject to a common $^{5}$ downward sloping demand from domestic consumers and foreign importers of elasticity $\zeta$ as in (7), and $M C_{t}=P_{H, t}^{W} / P_{H, t}$ are marginal costs. The solution to this is

$$
E_{t} \sum_{k=0}^{\infty} \xi_{H}^{k} D_{t, t+k} Y_{t+k}(f)\left[\hat{P}_{H t}(f)-\frac{\zeta}{(\zeta-1)} P_{H, t+k} M C_{t+k}\right]=0,
$$

and by the law of large numbers the evolution of the price index is given by

$$
P_{H, t+1}^{1-\zeta}=\xi_{H}\left(P_{H, t}\right)^{1-\zeta}+\left(1-\xi_{H}\right)\left(\hat{P}_{H, t+1}(f)\right)^{1-\zeta} .
$$

\section{Capital Producers}

As in Smets and Wouters (2003), we introduce the delayed response of investment observed in the data. Capital producers combine existing capital, $K_{t}$, leased from the entrepreneurs to transform an input $I_{t}$, gross investment, into new capital according to

$$
K_{t+1}=(1-\delta) K_{t}+\left(1-S\left(X_{t}\right)\right) I_{t} ; S^{\prime}, S^{\prime \prime} \geq 0 ; S(1)=S^{\prime}(1)=0,
$$

where $X_{t} \equiv I_{t} /\left(I_{t-1}\right)$. This captures the ideas that adjustment costs are associated with changes rather than levels of investment. ${ }^{6}$ Gross investment consists of domestic and foreign final goods

$$
I_{t}=\left[\mathrm{w}_{I}^{1 / \rho_{I}} I_{H, t}^{\left(\rho_{I}-1\right) / \rho_{I}}+\left(1-\mathrm{w}_{I}\right)^{1 / \rho_{I}} I_{F, t}^{\left(\rho_{I}-1\right) / \rho_{I}}\right]^{\rho_{I} /\left(1-\rho_{I}\right)},
$$

where weights in investment are defined as in the consumption baskets; namely

$$
\mathrm{w}_{I}=1-(1-n)\left(1-\omega_{I}\right) ; \quad \mathrm{w}_{I}^{*}=1-n\left(1-\omega_{I}^{*}\right),
$$

with investment price given by

$$
P_{I, t}=\left[\mathrm{w}_{I}\left(P_{H, t}\right)^{1-\rho_{I}}+\left(1-\mathrm{w}_{I}\right)\left(P_{F, t}\right)^{1-\rho_{I}}\right]^{1 /\left(1-\rho_{I}\right)} .
$$

4. Thus, we can interpret $1 /\left(1-\xi_{H}\right)$ as the average duration for which prices are left unchanged.

5. Recall that we have imposed a symmetry condition $\zeta=\zeta^{*}$ at this point; that is, the elasticity of substitution between differentiated goods produced in any one bloc is the same for consumers in both blocs.

6. In a balanced growth steady-state adjustment, costs are associated with change relative to trend so that the conditions on $S(\cdot)$ along the balanced growth path become $S(1+g)=$ $S^{\prime}(1+g)=0$. 
Capital producers choose the optimal combination of domestic and foreign inputs according to the same form of intratemporal first-order conditions as for consumption:

$$
I_{H, t}=\mathrm{w}_{I}\left(\frac{P_{H, t}}{P_{I, t}}\right)^{-\rho_{I}} I_{t} ; \quad I_{F, t}=\left(1-\mathrm{w}_{I}\right)\left(\frac{P_{F, t}}{P_{I, t}}\right)^{-\rho_{I}} I_{t} .
$$

The capital producing firm at time 0 then maximizes expected discounted profits $^{7}$

$$
E_{t} \sum_{t=0}^{\infty} D_{0, t}\left[Q_{t}\left(1-S\left(X_{t}\right)\right) I_{t}-\frac{P_{I, t} I_{t}}{P_{t}}\right]
$$

which, with $X_{t} \equiv I_{t} /\left(I_{t-1}\right)$, results in the first-order condition

$$
Q_{t}\left(1-S\left(X_{t}\right)-X_{t} S^{\prime}\left(X_{t}\right)\right)+E_{t}\left[\frac{1}{\left(1+R_{t+1}\right)} Q_{t+1} S^{\prime}\left(X_{t}\right) \frac{I_{t+1}^{2}}{I_{t}^{2}}\right]=\frac{P_{I, t}}{P_{t}} .
$$

\subsubsection{The Equilibrium, Fiscal Policy, and Foreign Asset Accumulation}

In equilibrium, goods markets, money markets, and the bond market are all clear. Equating the supply and demand of the home consumer good and assuming that government expenditure, taken as exogenous, goes exclusively on home goods, we obtain ${ }^{8}$

$$
Y_{t}=C_{H, t}+C_{H, t}^{e}+I_{H, t}+\frac{1-v}{v}\left[C_{H, t}^{*}+C_{H, t}^{e *}+I_{H, t}^{*}\right]+G_{t} .
$$

Fiscal policy is rudimentary: a balanced government budget constraint is given by

$$
P_{H, t} G_{t}=T_{t}+M_{H, t}-M_{H, t-1} .
$$

Adjustments to the taxes, $T_{t}$, in response to shocks to government spending away from the steady state are assumed to be nondistortionary.

Let $\sum_{h=1}^{v} B_{F, t}(h)=v B_{F, t}$ be the net holdings by the household sector of foreign bonds. Summing over the household budget constraints (including entrepreneurs and capital producers), noting that net holdings of domestic bonds are zero (since home bonds are not held by foreign households), and subtracting (39), we arrive at the accumulation of net foreign assets:

$$
\begin{aligned}
P_{B, t}^{*} S_{t} B_{F, t}+S_{t} M_{F, t}= & S_{t} B_{F, t-1}+S_{t} M_{F, t-1}+W_{t} L_{t}+\Gamma_{t}+\left(1-\xi_{e}\right) P_{t} V_{t} \\
& +P_{t} Q_{t}\left(1-S\left(X_{t}\right)\right) I_{t}-P_{t} C_{t}-P_{t} C_{t}^{e}-P_{I, t} I_{t}-P_{H, t} G_{t} \\
\equiv & S_{t} B_{F, t-1}+S_{t} M_{F, t-1}+T B_{t}
\end{aligned}
$$

where the trade balance, $T B_{t}$, is given by the national accounting identity

7. This ignores leasing costs, which Gertler, Gilchrist, and Natalucci (2003) show to be of second-order importance.

8. Note that all aggregates, $Y_{t}, C_{H, t}$, and so forth are expressed in per capita (household) terms. 


$$
P_{H, t} Y_{t}=P_{t} C_{t}+P_{t} C_{t}^{e}+P_{I, t} I_{t}+P_{H, t} G_{t}+T B_{t} .
$$

This completes the model. Given nominal interest rates $R_{n, t}, R_{n, t}^{*}$, the money supply is fixed by the central banks to accommodate money demand. By Walras' Law we can dispense with the bond market equilibrium condition. Then the equilibrium is defined at $t=0$ as stochastic sequences $C_{t}, C_{t}^{e}$, $C_{H, t}, C_{F, t}, P_{H, t}, P_{F, t}, P_{t}, M_{H, t}, M_{F, t}, B_{H, t}, B_{F, t}, W_{t}, Y_{t}, L_{t}, P_{H, t}^{0}, P_{t}^{I}, K_{t}, I_{t}, Q_{t}, V_{t}$; foreign counterparts $C_{t}^{*}$, and so forth, $R E R_{t}$, and $S_{t}$, given the monetary instruments $R_{n, t}, R_{n, t}^{*}$, and exogenous processes.

\subsubsection{Specialization of the Household's Utility Function}

The choice of utility function must achieve two objectives. The first, as in Felices and Tuesta (2006), is to provide a channel by which dollarization affects the marginal utility of consumption. This is achieved by a utility function that is nonseparable in consumption and money balances. The second objective is to have a model consistent with the balanced growth path (BGP) set out in previous sections. As pointed out in Barro and Sala-i-Martin (2004, chapter 9), this requires a careful choice of the form of the utility as a function of consumption and labor effort. Again, as in Gertler, Gilchrist, and Natalucci (2003), it is achieved by a utility function that is nonseparable, this time in the latter two arguments.

A utility function of the form

$$
U \equiv \frac{\left(\varepsilon_{t}+1\right)\left[\Phi(h)^{1-\varrho}\left(1-L_{t}(h)\left(1-\varepsilon_{L, t}\right)\right)^{\circ}\right]^{1-\sigma}}{1-\sigma}
$$

where

$$
\Phi_{t}(h) \equiv\left[b\left(C_{t}(h)-h_{C} C_{t-1}\right)^{(\theta-1) / \theta}+(1-b) Z_{t}(h)^{(\theta-1) / \theta}\right]^{\theta /(\theta-1)}
$$

(40) $Z_{t}(h) \equiv$

$\left[a\left(\frac{\left(\varepsilon_{M_{H}, t}+1\right) M_{H, t}(h)}{P_{t}}\right)^{\left(x_{M}-1\right) / \chi_{M}}+(1-a)\left(\frac{\left(\varepsilon_{M_{F}, t}+1\right) S_{t} M_{F, t}(h)}{P_{t}}\right)^{\left(x_{M}-1\right) / \chi_{M}}\right]^{\times M /\left(\chi_{M}-1\right)}$,

and where labor supply, $L_{t}(h)$, measured as a proportion of a day, normalized at unity, satisfies these two requirements. ${ }^{9}$ For this function, $U_{\Phi L}>0$, so that consumption and money holdings together, and leisure (equal to $\left.1-L_{t}[h]\right)$ are substitutes.

\subsubsection{State Space Representation}

We linearize around a deterministic zero inflation, balanced growth steady state. We can write the two-bloc model in state space form as

9. A balanced growth path (BGP) requires that the real wage, real money balances, and consumption grow at the same rate at the steady state with labor supply steady. It is straightforward to show that (42) has these properties. 


$$
\begin{aligned}
{\left[\begin{array}{c}
\mathbf{z}_{t+1} \\
E_{t} \mathbf{x}_{t+1}
\end{array}\right] } & =A\left[\begin{array}{l}
\mathbf{z}_{\mathbf{t}} \\
\mathbf{x}_{t}
\end{array}\right]+B \mathbf{o}_{t}+C\left[\begin{array}{c}
r_{n, t} \\
r_{n, t}^{*}
\end{array}\right]+D \mathbf{v}_{t+1} \\
\mathbf{o}_{t} & =H\left[\begin{array}{l}
\mathbf{z}_{t} \\
\mathbf{x}_{t}
\end{array}\right]+J\left[\begin{array}{l}
r_{n, t} \\
r_{n, t}^{*}
\end{array}\right],
\end{aligned}
$$

where $\mathbf{z}_{t}$ is a vector of predetermined exogenous variables, $\mathbf{x}_{t}$ are nonpredetermined variables, and $\mathbf{o}_{t}$ is a vector of outputs. ${ }^{10}$ Matrices $A, B$, and so forth are functions of model parameters. Rational expectations are formed assuming an information set $\left\{z_{1, s}, z_{2, s}, x_{s}\right\}, s \leq t$, the model and the monetary rule. Details of the linearization are provided in appendix B.

\subsubsection{The Small Open Economy}

Following Felices and Tuesta (2006), we can now model a small open economy by letting its relative size in the world economy $n \rightarrow 0$ while retaining its linkages with the rest of the world (ROW). In particular, the demand for exports is modeled in a consistent way that retains its dependence on shocks to the home and ROW economies. We now need a fully articulated model of the ROW. From (6) we have that $\mathrm{w} \rightarrow \omega$ and $\mathrm{w}^{*} \rightarrow 1$ as $n \rightarrow 0$. Similarly, for investment we have $\mathrm{w}_{I} \rightarrow \omega_{I}$ and $\mathrm{w}_{I}^{*} \rightarrow 1$ as $n \rightarrow 0$. It seems at first glance then that the ROW becomes closed and therefore exports from our small open economy must be zero. However, this is not the case. Consider the linearized form of the output demand equations in the two blocs:

$$
\begin{aligned}
y_{t}= & \alpha_{C, H} c_{t}+\alpha_{C, H}^{e} c_{t}^{e}+\alpha_{C, H}^{*} c_{t}^{*}+\alpha_{I, H} i_{t}+\alpha_{I, H}^{*} i_{t}^{*}+\alpha_{G} g_{t} \\
& +\left[\mu\left(\alpha_{C, H}+\alpha_{C, H}^{e}\right)(1-\mathrm{w})+\mu^{*} \alpha_{C, H}^{*} \mathrm{~W}^{*}+\rho_{I} \alpha_{I, H}\left(1-\mathrm{w}_{I}\right)+\rho_{I}^{*} \alpha_{I, H}^{*} \mathrm{w}_{I}^{*}\right] \tau_{t} \\
y_{t}^{*}= & \alpha_{C, F}^{*} c_{t}^{*}+\alpha_{C, F} c_{t}+\alpha_{C, F}^{e} c_{t}^{e}+\alpha_{I, F}^{*} i_{t}^{*}+\alpha_{I, F} i_{t}+\alpha_{G}^{*} g_{t}^{*} \\
& -\left[\mu^{*}\left(\alpha_{C, F}^{*}\left(1-\mathrm{w}^{*}\right)+\mu \alpha_{C, F} \mathrm{w}+\rho_{I}^{*} \alpha_{I, F}^{*}\left(1-\mathrm{w}_{I}^{*}\right)+\rho_{I} \alpha_{I, F} \mathrm{w}_{I}\right] \tau_{t},\right.
\end{aligned}
$$

where the elasticities and their limits as $n \rightarrow 0$ are given by

$$
\begin{aligned}
\alpha_{C, H} & =\frac{\mathrm{w}\left(1-s_{e}\right) C}{Y} \rightarrow \frac{\omega\left(1-s_{e}\right) C}{Y} \\
\alpha_{C, H}^{e} & =\frac{\mathrm{w} s_{e} C}{Y} \rightarrow \frac{\omega s_{e} C}{Y} \\
\alpha_{C, H}^{*} & =\frac{\left(1-\mathrm{w}^{*}\right) C^{*}}{Y^{*}} \frac{(1-n) Y^{*}}{n Y} \rightarrow \frac{\left(1-\omega^{*}\right) C^{*}}{Y^{*}} \frac{Y^{*}}{Y} \\
\alpha_{G} & =\frac{G}{Y}
\end{aligned}
$$

10. We define all lowercase variables as proportional deviations from this baseline steady state except for rates of change, which are absolute deviations. That is, for a typical variable $X_{t}, x_{t}=X_{t}-X / X \simeq \log \left(X_{t} / X\right)$, where $X$ is the baseline steady state. For variables expressing a rate of change over time such as the nominal interest rate $r_{n, t}$ and inflation rates, $x_{t}=X_{t}-X$. 


$$
\begin{aligned}
\alpha_{I, H} & =\frac{\mathrm{w}_{I} I}{Y} \rightarrow \frac{\omega_{I} I}{Y} \\
\alpha_{I, H}^{*} & =\frac{\left(1-\mathrm{w}_{I}^{*}\right) I^{*}}{Y^{*}} \frac{(1-n) Y^{*}}{n Y} \rightarrow \frac{\left(1-\omega_{I}^{*}\right) I^{*}}{Y^{*}} \frac{Y^{*}}{Y} \\
\alpha_{C, F}^{*} & =\frac{\mathrm{w}^{*} C^{*}}{Y^{*}} \rightarrow \frac{C^{*}}{Y^{*}} \\
\alpha_{C, F}^{e *} & =0 \\
\alpha_{C, F} & =\frac{(1-\mathrm{w}) C}{Y} \frac{n Y}{(1-n) Y^{*}} \rightarrow 0 \\
\alpha_{C, F}^{e} & =\frac{(1-\mathrm{w})\left(1-\xi^{e}\right) n_{k} k_{y}}{\xi_{e}} \frac{n Y}{(1-n) Y^{*}} \rightarrow 0 \\
\alpha_{G}^{*} & =\frac{G^{*}}{Y^{*}} \\
\alpha_{I, F}^{*} & =\frac{\mathrm{w}_{I}^{*} I^{*}}{Y^{*}} \rightarrow \frac{I^{*}}{Y^{*}} \\
\alpha_{I, F} & =\frac{\left(1-\mathrm{w}_{I}\right) I}{Y^{*}} \frac{n Y}{(1-n) Y^{*}} \rightarrow 0 .
\end{aligned}
$$

Thus, we see that from the viewpoint of the ROW our small open economy becomes invisible, but not vice versa. Exports to and imports from the ROW are now modeled explicitly in a way that captures all the interactions between shocks in the ROW and the transmission to the small open economy.

\subsubsection{Calibration}

\section{Home Bias Parameters}

The bias parameters we need to calibrate are: $\omega, \omega^{*}, \omega_{I}$, and $\omega_{I}^{*}$. Let in the steady state $C^{e}=s_{e} C$ be consumption by entrepreneurs, and $c_{y}=C / Y$. Let $c s_{\text {imports }}$ be the GDP share of imported consumption of the foreign $(F)$ consumption good. Let $c s_{\text {exports }}$ be the GDP share of exports of the home $(H)$ consumption good. Then we have that

$$
\begin{aligned}
& \alpha_{C, H}=\frac{C_{H}}{Y}=\frac{\omega C}{Y}=\left(c_{y}-c s_{\text {imports }}\right)\left(1-s_{e}\right) \\
& \alpha_{C, H}^{e}=\frac{C_{H}^{e}}{Y}=\frac{\omega C^{e}}{Y}=\left(c_{y}-c s_{\text {imports }}\right) s_{e} \\
& \alpha_{C, H}^{*}=\frac{C_{H}^{*}}{Y}=\frac{\left(1-\omega^{*}\right) C^{*}}{Y^{*}} \frac{Y^{*}}{Y}=c s_{\text {exports }} .
\end{aligned}
$$


Similarly, for investment define $i s_{\text {imports }}$ to be the GDP share of imported investment of the $F$ investment and $i s_{\text {exports }}$ be the GDP share of exports of $H$ investment good. Then with $i_{y}=I / Y$, we have

$$
\begin{aligned}
& \alpha_{I, H}=\frac{I_{H}}{Y}=\frac{\omega_{I} I}{Y}=i_{y}-i s_{\text {imports }} \\
& \alpha_{I, H}^{*}=\frac{I_{H}^{*}}{Y}=\frac{\left(1-\omega_{I}^{*}\right) I^{*}}{Y^{*}} \frac{Y^{*}}{Y}=i s_{\text {exports }}
\end{aligned}
$$

in the steady state. We linearize around a zero trade balance $T B=0$, so we require

$$
c s_{\text {imports }}+i s_{\text {imports }}=c s_{\text {exports }}+i s_{\text {exports }}
$$

in which case $\alpha_{C, H}+\alpha_{C, H}^{e}+\alpha_{C, H}^{*}+\alpha_{I, H}+\alpha_{I, H}^{*}=c_{y}+i_{y}$, as required. Thus, we can use trade data for consumption and investment goods, consumption shares, and relative per capita GDP to calibrate the bias parameters $\omega, \omega^{*}$, $\omega_{I}$, and $\omega_{I}^{*}$. We need the home country biases elsewhere in the model, but for the ROW we simply put $\omega^{*}=\omega_{I}^{*}=1$ everywhere else, so these biases are not required as such.

\section{Calibration of Household Preference Parameters}

We now show how observed data on the household wage bill as a proportion of total consumption, real money balances as a proportion of consumption, and estimates of the elasticity of the marginal utility of consumption with respect to total money balances can be used to calibrate the preference parameters $\varrho, b$, and $\theta$ in (42).

Calibrating parameters to the BG steady state, we first note that from (16) we have

$$
\frac{(\eta-1)}{\eta} \frac{W(1-L)}{P C}=\frac{\varrho \Phi}{C\left(1-h_{C}\right) \Phi_{C}(1-\varrho)} .
$$

In (49), $W(1-L) / P C$ is the household wage bill as a proportion of total consumption, which is observable. From the definition of $\Phi$ in (43), we have that

$$
\frac{\Phi}{C \Phi_{C}}=\frac{(1-b) c z^{(1-\theta) / \theta}+b}{b}
$$

where $c z \equiv\left(C\left(1-h_{C}\right)\right) / Z$ is the effective-consumption-real money balance ratio (allowing for external habit). From (42), the elasticity the marginal utility of consumption with respect to total money balances, $\Psi$, say, is given by

$$
\frac{Z U_{C Z}}{U_{C}} \equiv \Psi=\frac{(1-b)[(1-\varrho)(1-\sigma)-1+(1 / \theta)]}{b c z(\theta-1) / \theta+1-b} .
$$

From the first-order conditions in the steady state (A.26) and (A.27) with $R_{n}=R_{n}^{*}=R$ we have 


$$
\frac{b\left(1-h_{C}\right)}{1-b} c z^{-1 / \theta}=\frac{1+R}{R} .
$$

Thus, given $\sigma, \beta, g, h_{C},(W(1-L)) / P C, c z$, and $\Psi$, equations (49) through (52) can be solved for $\varrho, b$, and $\theta$. Appendix $C$ provides further details ${ }^{11}$ of $\Psi \in[0,0.01]$. Since $\Psi>0$, we impose on our calibration the property that money and consumption are complements.

\section{Remaining Parameters}

As far as possible, parameters are chosen based on quarterly data for Peru. Elsewhere the parameters reflect broad characteristics of emerging economies. A variety of sources are used: for Peru we draw upon Castillo, Montoro, and Tuesta (2006) (henceforth, CMT). For emerging economies more generally and for parameters related to the financial accelerator we use Gertler, Gilchrist, and Natalucci (2003) (henceforth, GGN) and Bernanke, Gertler, and Gilchrist (1999) (henceforth, BGG). The rest of the world is represented by U.S. data. Here we draw upon Levin et al. (2006) (henceforth, LOWW). In places, we match Peru with European estimates using Smets and Wouters (2003) (henceforth, SW). Appendix C provides full details of the calibration.

\subsection{Monetary Policy Interest Rate Rules}

In line with the literature on open economy interest rate rules (see, for example, Benigno and Benigno [2004]), we assume that the central bank in the emerging market bloc has three options: (a) set the nominal interest to keep the exchange rate fixed (fixed exchange rates, "FIX"); (b) set the interest rate to minimize deviations of domestic or CPI inflation from a predetermined target (inflation targeting under fully flexible exchange rates, "FLEX(D)" or "FLEX(C)"); or finally, (c) follow a hybrid regime, in which the nominal interest rates respond to both inflation deviations from target and exchange rate deviations from a certain level (managed float, "HYB"). Many emerging market countries follow one or another of these options and most are likely to in the near future. Formally, the rules are as follows.

Fixed Exchange Rate Regime, "FIX" In a simplified model without an exchange rate premium as analyzed in section 5.4 , we show this is implemented by

$$
r_{n, t}=r_{n, t}^{*}+\theta_{s} s_{t},
$$

where any $\theta_{s}>0$ is sufficient to the regime. In our full model with an exchange rate premium, we implement "FIX" as a "HYB" regime following, with feed- 
back coefficients chosen to minimize a loss function that includes a large penalty on exchange rate variability. (Note that values for the loss function reported shown in the following remove the latter contribution.)

Inflation Targets under a Fully Flexible Exchange Rate, "FLEX(D)" or "FLEX $(C)$ " This takes the form of Taylor rule with domestic or CPI inflation and output growth targets:

$$
\begin{aligned}
& r_{n, t}=\rho r_{n, t-1}+\theta_{\pi} E_{t} \pi_{H, t}+\theta_{y} \Delta y_{t} \\
& r_{n, t}=\rho r_{n, t-1}+\theta_{\pi} E_{t} \pi_{t}+\theta_{y} \Delta y_{t},
\end{aligned}
$$

where $\rho \in[0,1]$ is an interest rate smoothing parameter.

Managed Float, "HYB" In this rule the exchange rate response is direct rather than indirect as in the CPI inflation rule (55): ${ }^{12}$

$$
r_{n, t}=\rho r_{n, t-1}+\theta_{\pi} E_{t} \pi_{H, t}+\theta_{y} \Delta y_{t}+\theta_{s} s_{t} .
$$

In all cases we assume that the central bank in the emerging market bloc enjoys full credibility. Although this assumption may have been considered heroic a few years ago, today there are several emerging market countries that have succeeded in stabilizing inflation at low levels and have won the trust of economic agents at home and abroad including economies with a history of high or hyper-inflation (e.g., Brazil, Israel, Peru, and Mexico, among others. See Batini, Breuer, and Kochhar [2006]). Accounting for imperfect credibility of the central bank remains nonetheless important for many other emerging market countries, and can lead to higher stabilization costs than under full credibility (under inflation targeting and floating exchange rate, see Aoki and Kimura [2007]) or even sudden stops and financial crises (under fixed exchange rates, see IMF [2005]).

\subsection{Transactions Dollarization in a Model without Capital}

The stability and determinacy properties of various monetary rules provide a good indication of their stabilization performance. However, the full model with capital, the financial accelerator, and both transactions and liability dollarization has high-order dynamics and is not analytically tractable. In order to throw some light on the numerical results that follow, in

12. Rule (52) describes one of many possible specifications of a managed float, namely one where the central bank resists deviations of the exchange rate from a certain level - considered to be the equilibrium - as well as deviations of inflation from target and output from potential. An equally plausible specification involves a feedback on the rate of change of the exchange rate, in which case the central bank aim is to stabilize exchange rate volatility; that is, the pace at which the domestic currency appreciates or depreciates over time. For a discussion see Batini, Harrison, and Millard (2003). To limit the number of simulations and results to be compared, here we limit ourselves to one specification only. 
this section we therefore study a special case of the model that suppresses capital, the associated financial accelerator, habit in consumption, and the exchange rate risk premium facing households (i.e., $h_{C}=\delta_{r}=0$ ). The analysis provides results on the consequences of transactions dollarization for a simple current domestic inflation targeting rule in the form (54) with $\theta_{y}=0$.

We are interested in establishing the conditions for this current domestic inflation rule to be saddle-path stable. Exogenous processes play no part in this property (so long as they themselves are stable or saddle-path stable, a property we assume). Ignoring these processes we can express the linearized system in terms of the marginal utilities of consumption, $u_{c, t}$ in deviation form, ${ }^{13}$ and the marginal disutility of labor $\left(u_{l, t}\right)$, which holds for any choice of utility function. After some effort this takes the form

$$
\begin{gathered}
E_{t} u_{c, t+1}=u_{c, t}-\omega\left(r_{n, t}-E_{t} \pi_{H, t+1}\right) \\
\beta E_{t} \pi_{H, t+1}=\pi_{H, t}-\lambda_{H}\left(u_{l, t}-\frac{1}{\omega} u_{c, t}\right) \\
y_{t}=l_{t}=\alpha_{C, H} c_{t}-v u_{c, t},
\end{gathered}
$$

where $\lambda_{H}=\left(\left(1-\beta \xi_{H}\right)\left(1-\xi_{H}\right)\right) / \xi_{H}$ and $\nu=1 / \omega\left(\mu \alpha_{C, H}(1-\omega)+\mu^{*} \alpha_{C, H}^{*}\right)$. After further algebra, using the expressions for $u_{c, t}, u_{l, t}, y_{t}, c_{t}$ in appendix $\mathrm{B}$, we arrive at the following specification for $\pi_{H, t}$ expressed solely in terms of $u_{c, t}$ and $r_{n, t}$ :

$$
\beta E_{t} \pi_{H, t+1}=\pi_{H, t}+\gamma u_{c, t}-\kappa r_{n, t},
$$

where

$$
\begin{aligned}
\begin{aligned}
\gamma=\lambda_{H}\left(\frac{L}{1-L} \frac{1-\omega}{\omega}+\right. & \frac{L}{1-L} v \\
& \left.\quad+\frac{\left(1+(L / 1-L) \omega c_{y}\right)(1+\nu)[\rho(\sigma-1) L] /(1-L)}{1+(\sigma-1)(1-\rho)-\rho(\sigma-1) \omega c_{y}(L / 1-L)}\right)
\end{aligned} \\
\kappa=\bar{a} \lambda_{H} \Phi_{L}+\frac{\bar{a} \lambda_{H}\left(1+(L / 1-L) \omega c_{y}\right) \omega}{1+(\sigma-1)(1-\rho)-\rho(\sigma-1) \omega c_{y}(L / 1-L)},
\end{aligned}
$$

and $\Phi, \Phi_{L}, b_{1}, \bar{a}$ aand $\alpha$ are defined in appendix B.

We restrict ourselves to a range of parameter values for which $\sigma>1$ and $(1-\rho)-\rho \omega c_{y} L /(1-L)>0$. Because $\omega c_{y} L /(1-L), \ll 1$ this is a very weak condition that our calibrated values easily satisfy. Then $\gamma>0$. Furthermore, $\kappa$ can be either positive or negative. By definition $\varpi_{L}$, the elasticity of the marginal utility of work effort with respect to the nominal interest rate is

13. Recall that all lower case variables are proportional deviations from the steady state, except for rates of change, which are absolute deviations. See note 12. 
always positive. But the sign of $\varpi$, the corresponding elasticity of the marginal utility of consumption, depends on whether consumption and real balances are substitutes or complements. If they are substitutes then $\varpi>$ 0 and then $\kappa>0$. But here we assume that they are complements, in which case $\kappa$ can take either sign. Our results following are sensitive to this.

In fact, for our chosen calibration, $\kappa$ is comfortably positive. This means that the nominal interest rate impacts on the economy through two channels. First, given expectations of CPI inflation, an increase in the nominal interest rate reduces the expected real interest rate and reduces demand from consumption. This will cause the domestic inflation rate to fall in the usual way. But with a nonseparable utility function, there is a second channel of influence through the supply-side that sees marginal cost, and therefore the inflation rate, rise as the result of an increase in the interest rate. Thus, with $\kappa>0$ supply and demand effects work in opposite directions and the supply side effect will tend to undermine the stabilizing demand side effect. However, $\kappa$ depends on the degree of transactions dollarization, $\kappa=0$, when there is complete dollarization $(a=\bar{a}=0)$ and therefore the supply effect closes down. This eliminates a destabilizing effect, so as we approach complete transactions dollarization we should witness a more effective form of monetary stabilization.

Equations (57) and (60) form the basis for the analysis of the next section. The important feature of the modified Phillips curve, (60), with a nonseparable utility function in money and consumption, is the manner in which the domestic interest rate impacts on domestic inflation.

\subsubsection{Fixed Exchange Rate Regime (FIX)}

For the model without capital and an exchange rate risk premium, the saddle-path stability of the FIX regime is unambiguous as the following proposition indicates:

Proposition 1. Under regime FIX:

(a) The system is stable and determinate for all values of $\theta_{s}>0$.

(b) The nominal exchange rate is fixed.

\section{PROOF. See appendix D.}

As Benigno and Benigno (2004) have stressed, the feedback from the exchange rate to the interest rate is not operative in the equilibrium because $s_{t}=0$ at all times. Rather, it is the belief that the monetary authority responds in this way even for very small $\theta_{s}$ that maintains a fixed exchange rate. With such a regime, the domestic interest rate that enters the Phillips curve in (60) remains fixed too, so neither the nonseparable form of the utility function nor the existence of dollarization has an impact on the stability properties of the system. 


\subsubsection{Domestic Inflation Targeting Rule (FLEX (D))}

Now consider the rule (54). In the rest of this section we focus on inflationtargeting interest rate rules that respond only to domestic inflation, but not to output growth. This makes the analysis tractable, but there are other reasons for examining such rules. First, pure inflation-targeting or inflationtargeting with a managed exchange rate corresponds to the objectives of many modern central banks. Second, it is of intrinsic interest to see to what extent an economy can be stabilized with the simplest possible form of rule that only tracks one nominal variable. With this form of rule we can then show the following.

PROPOSITION 2. Under FLEX $(D)$ :

(a) If $2 \kappa>\omega \gamma>(1-\rho) \kappa$, then the system is stable and determinate for the range $1<\theta_{\pi}<((1+\rho)(2(1+\beta)+\gamma \omega)) /((1-\rho)(2 \kappa-\gamma \omega)) \triangleq \bar{\theta}_{\pi}$.

(b) If $\omega \gamma>2 \kappa$, then any feedback $\theta_{\pi}>1$ from current inflation leads to stability and determinacy.

Proof. See appendix D. An immediate corollary follows.

COROLlary 1. As $\rho \rightarrow 1$ and we approach an integral rule, then the range $\left[1, \bar{\theta}_{\pi}\right]$ in (a) becomes infinite.

Thus, interest rate smoothing helps to induce determinacy-a result obtained in Batini, Levine, and Pearlman (2004) for both current and forward-looking inflation targeting rules. Furthermore, we show in appendix $\mathrm{D}$ that $\kappa$ decreases with increasing dollarization in the range $0<a<1 / 2$, which leads to another corollary.

COROLlaRY 2. For high levels of dollarization a $<1 / 2$, as dollarization increases further, then $\mathrm{\kappa}$ falls and the determinacy range for $\theta_{\pi}$ increases.

Thus, for a current domestic inflation rule, a high degree of transactions dollarization poses no problems for stability and determinacy; in fact, it helps to avoid both problems. The intuition behind this result is that with $\kappa>0$, a case easily supported by the calibration, supply and demand effects of nominal interest rate changes operate in opposite directions. But transactions dollarization closes down the supply-side effect and therefore helps the stabilization process.

Figure 5.1 illustrates our result using our central calibration. We see that condition (a) is just satisfied for all degrees of transactions dollarization, $a \in[0,1]$, if $\rho>0.25$, which is a very modest degree of interest rate smoothing. These results have been obtained for a simple model where many of the features in our full model have been suppressed. Nevertheless, they are suggestive of the effects of transactions dollarization on the stabilization properties of a simple current domestic inflation rule in the full model. 

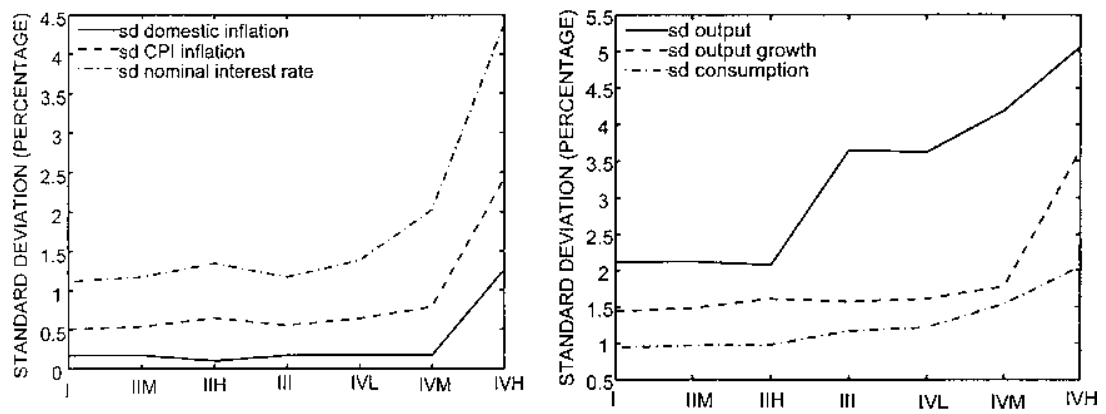

Fig. 5.1 Standard deviations of key variables

\subsection{Optimal Monetary Policy, Volatility, and Impulse Responses}

How do financial frictions and dollarization in emerging market economies affect the transmission mechanism of monetary policy and the volatilities of output, inflation, and other key variables? To answer this question we do two things. First, we parameterize four representations of the model with increasing frictions and dollarization, and solve them subject to the corresponding optimal monetary policy rule based on maximizing the household's utility. (Later, in section 5.6, this provides a benchmark against which to assess the welfare implications of the fixed exchange rate regime and various Taylor-type flexible exchange rate rules.) We then compare the volatilities delivered by each model for key macrovariables, including inflation and output. Second, we analyze how transmission of shocks is affected by frictions and dollarization by tracing impulse responses to two key shocks.

\subsubsection{Optimal Monetary Policy and Volatilities}

We adopt a linear-quadratic framework for the optimization problem facing the monetary authority. This is particularly convenient as we can then summarize outcomes in terms of unconditional (asymptotic) variances of macroeconomic variables and the local stability and determinacy of particular rules. The framework also proves useful for addressing the issue of the zero lower bound on the nominal interest rate.

Following Woodford (2003), we adopt a "small distortions" quadratic approximation to the household's single period utility that is accurate as long as the zero-inflation steady state is close to the social optimum. There are three distortions that result in the steady-state output being below the social optimum: namely, output and labor market distortions from monopolistic competition and distortionary taxes required to pay for government provided services. Given our calibration these features would make our distortions far from small. However, there is a further distortion, external habit in 
consumption, that in itself raises the equilibrium steady-state output above the social optimum. If the habit parameter $h_{C}$ is large enough, the two sets of effects can cancel out and thus justify our small distortions approximation. In fact, this is the case in our calibration. ${ }^{14}$

From appendix E our quadratic approximation to the household's intertemporal expected loss function is given by

$$
\Omega_{0}=E_{t}\left[(1-\beta) \sum_{t=0}^{\infty} \beta^{t} L_{t}\right],
$$

where

$$
\begin{aligned}
2 L_{t}= & w_{c}\left(\frac{c_{t}-h_{C} c_{t-1}}{1-h_{C}}\right)^{2}+w_{\tau} \tau_{t}^{2}+w_{c l}\left(\frac{c_{t}-h_{C} c_{t-1}}{1-h_{C}}\right) l_{t}+w_{l} l_{t}^{2} \\
& +w_{k}\left(k_{t-1}-l_{t}\right)^{2}-w_{a y} y_{t} a_{t}+w_{c i r} c i_{t} \tau_{t}+w_{c l s \tau} c l s_{t} \tau_{t}+w_{\pi} \pi_{H, t}^{2} \\
c i_{t} \equiv & \mu \omega(1-\omega) c_{y} c_{t}+\mu\left(1-\omega^{*}\right) c_{y} c_{t}^{*}+\rho_{I} \omega_{I}\left(1-\omega_{I}\right) i_{y} i_{t}+\rho_{I}^{*}\left(1-\omega_{I}^{*}\right) i_{y} i_{t}^{*} \\
c l s_{t} \equiv & {[(1-\sigma)(1-\varrho)-1] \frac{c_{t}^{*}-h c_{t-1}^{*}}{1-h}-(1-\sigma) \varrho \frac{L^{*} l_{t}^{*}}{1-L^{*}}, }
\end{aligned}
$$

and the weights $w_{c}, w_{\tau}$, and so forth, are defined in appendix E. Thus, from (62) welfare is reduced as a result of volatility in consumption adjusted to external habit $c_{t}-h_{C} c_{t-1}$; the terms of trade $\tau_{t}$, labor supply $l_{t}$, domestic inflation $\pi_{H, t}$, and foreign shocks. There are also some covariances that arise from the procedure for the quadratic approximation of the loss function. The policymaker's problem at time $t=0$ is then to minimize (61) subject to the model in linear state-space form given by (45), initial conditions on predetermined variables $z_{0}$, and the Taylor rule followed by the ROW. Details of the optimization procedure are provided in Levine, McAdam, and Pearl$\operatorname{man}(2007)$.

We parameterize the model according to five alternatives, ordered by increasing degrees of frictions and dollarization:

- Model I: no transaction dollarization, no financial accelerator, and no liability dollarization. This is a fairly standard small open economy model similar to many in the new-Keynesian open economy literature with the only nonstandard features being a nonseparable utility function in money balances, consumption, and leisure consistent with a balanced growth path and a fully articulated ROW bloc.

- Model II: transaction dollarization (TD) only (where the degree of TD is captured by $1-a$, where $a \in[0,1])$.

- Model III: financial accelerator (FA) only.

14. See Levine, McAdam, and Pearlman (2007) and Levine, Pearlman, and Pierse (2006) for a discussion of these issues. The former paper provides details of all the optimization procedures in this chapter. 
Expected welfare loss decomposition

\begin{tabular}{lcccc}
\hline & $\mathrm{I}$ & $\mathrm{II}(a=0.5)$ & $\mathrm{III}$ & $\mathrm{IV}(\varphi=0.5)$ \\
\hline$a_{t}$ & 0.8100 & 0.7779 & 0.6642 & 0.6980 \\
$g_{t}$ & 0.0438 & 0.0416 & 0.0417 & 0.0475 \\
$g_{t}^{*}$ & 0.0010 & 0.0001 & 0.0046 & 0.0046 \\
$\epsilon_{U I P, t}$ & 0.0567 & 0.0520 & 0.0884 & 0.0863 \\
$\epsilon_{R, t}^{*}$ & 0.0543 & 0.0240 & 0.0681 & 0.1406 \\
$\epsilon_{P, t}$ & 0.0196 & 0.0197 & 0.1731 & 0.5970 \\
All shocks & 0.9855 & 0.9152 & 1.0400 & 1.5742 \\
\hline
\end{tabular}

- Model IV: financial accelerator (FA) and liability dollarization (LD), assuming that firms borrow a fraction of their financing requirements $1-\varphi \in[0,1]$ in dollars.

- Model V: TD plus FA plus LD, where $a=\varphi=0.5$; that is, medium level TD and LD.

We subject all these variants of the model to six exogenous and independent shocks. Three of these-total factor productivity $\left(a_{t}\right)$, government spending $\left(g_{t}\right)$, and the external risk premium facing firms, $\epsilon_{P, t}$ - are domestic and three - a foreign demand counterpart to $g_{t}^{*}$, a country risk premium shock to the modified UIP condition, $\epsilon_{U I P, t}$, and shock to the foreign interest rate rule $\epsilon_{R, t}^{*}$ - originate from the ROW. The foreign bloc is fully articulated, so the effect of these shocks impacts on the domestic economy through changes in the demand for exports. Since the domestic economy is small, however, there is no corresponding effect of domestic shocks on the ROW. ${ }^{15}$

The first question we pose is what is the relative importance of these six shocks for the welfare of domestic households under optimal monetary policy? Table 5.1 provides the answer by carrying out an expected welfare decomposition ${ }^{16}$ with respect to the shocks for our four model variants. For both TD and LD we assume a degree of dollarization $1-a=1-\varphi=0.5$. Given our calibration, the most important shock is that to technology, irrespective of the existence of a FA or LD. But as these latter features are introduced in turn, the model economy becomes increasingly vulnerable to the three foreign shocks, with the contribution of technology falling from 82 percent in model I to 44 percent in model IV. Our earlier analysis of a model without capital suggested that TD improves stabilization. Table 5.1 confirms this for the full model —indeed, TD sees a reduction in the welfare loss emanating from all shocks.

15. Of course, the simulation results reported in the following depend on our calibration of both structural parameters and shocks, particularly on the parameters determining the exchange rate elasticity of trade and net worth. However, changing these with a plausible range does not affect the results qualitatively.

16. The expected welfare loss is the conditional loss in the vicinity of the steady state. 


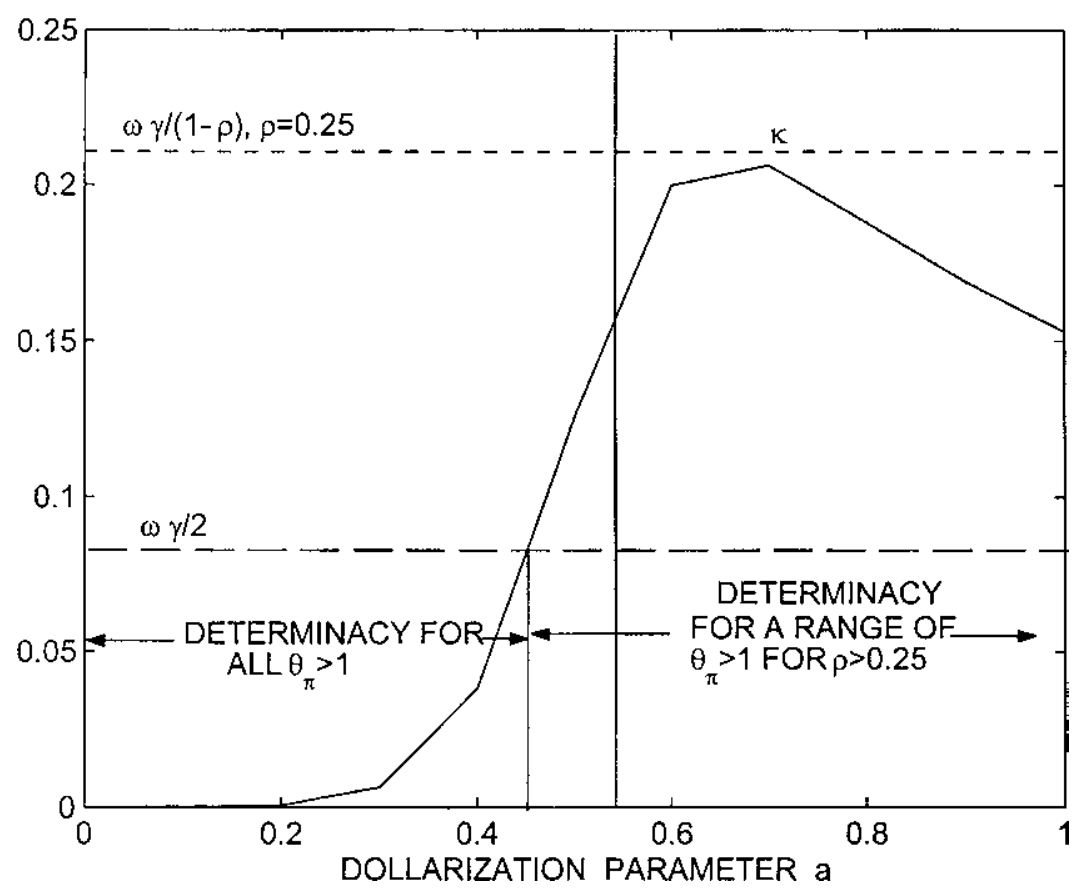

Fig. 5.2 Transactions dollarization and determinacy of current inflation rule

Figure 5.2 picks out some key variables and shows standard deviations associated with model I, model II with medium and high degrees of TD (IIM, IIH), and model III and model IV with low, medium, and high degrees of TD (IVL, IVM, IVH) under optimal policy. ${ }^{17}$ Table 5.2 presents volatility results for all model variables. This broadly reaffirms the general result that more frictions and liability dollarization trigger greater economic volatility. Investment, net worth, interest rate, and real exchange variability are particularly high for even moderate degrees of liability dollarization and financial acceleration, compared to a world without such features.

A number of further features of these volatilities deserve highlighting. First consider TD proceeding from the baseline model with no TD to the opposite extreme of full TD. As mentioned previously, welfare does not deteriorate but indeed increases, and this is confirmed by the reduction in variances of consumption, the terms of trade (implied by the lower variance of the real exchange rate), and inflation, which feature in the loss function. However, this comes at a cost of an increase in the variance of the nominal interest rate since TD closes down one channel for monetary intervention.

17. We do not show model $\mathrm{V}$ because adding TD has no visible implications for volatilities in the chart. 
Variances in percent ${ }^{2}$ and expected welfare loss

\begin{tabular}{lcccccccc}
\hline & & II & II & & IV & IV & IV & V \\
& I & $(a=0.5)$ & $(a=0)$ & III & $(\varphi=0.75)$ & $(\varphi=0.5)$ & $(\varphi=0)$ & $(a=\varphi=0.5)$ \\
\cline { 2 - 9 } & 4.50 & 4.53 & 4.31 & 13.3 & 13.1 & 17.5 & 25.6 & 17.8 \\
$\operatorname{var}\left(y_{t}\right)$ & 0.89 & 0.94 & 0.95 & 1.36 & 1.48 & 2.37 & 4.23 & 2.58 \\
$\operatorname{var}\left(c_{t}\right)$ & 9.67 & 9.78 & 9.72 & 139 & 117 & 138 & 44.2 & 135 \\
$\operatorname{var}\left(i_{t}\right)$ & 11.9 & 12.0 & 11.8 & 12.8 & 12.9 & 13.2 & 7.66 & 13.1 \\
$\operatorname{var}\left(q_{t}^{k}\right)$ & 0.72 & 0.58 & 0.39 & 1.19 & 1.22 & 1.83 & 30.3 & 1.61 \\
$\operatorname{var}\left(l_{t}\right)$ & 3.66 & 3.61 & 3.54 & 3.82 & 4.33 & 5.89 & 16.9 & 5.68 \\
$\operatorname{var}\left(r e r_{t}\right)$ & 0.03 & 0.03 & 0.01 & 0.03 & 0.03 & 0.03 & 1.59 & 0.03 \\
$\operatorname{var}\left(\pi_{H, t}\right)$ & 0.26 & 0.29 & 0.42 & 0.31 & 0.41 & 0.63 & 5.88 & 0.63 \\
$\operatorname{var}\left(\pi_{t}\right)$ & 1.24 & 1.37 & 1.81 & 1.37 & 1.93 & 4.13 & 19.2 & 4.17 \\
$\operatorname{var}\left(r_{n, t}\right)$ & 0 & 0 & 0 & 227 & 207 & 274 & 118 & 270 \\
$\operatorname{var}\left(n_{t}\right)$ & 0 & 1.33 & 2.02 & 2.03 & 2.19 & 1.67 & 2.18 \\
$\operatorname{var}\left(\theta_{t}\right)$ & 1.33 & 1.33 & 1.33 & 2.63 \\
$\operatorname{var}\left(\Delta y_{t}\right)$ & 2.08 & 2.21 & 2.60 & 2.47 & 2.60 & 3.16 & 13.31 & 3.18 \\
$\Omega_{0}$ & 0.986 & 0.915 & 0.778 & 1.040 & 1.156 & 1.574 & 19.14 & 1.466 \\
\hline
\end{tabular}

This higher interest rate has implications in terms of the zero lower bound (ZLB) constraint, an issue we return to in section 5.7.

Now consider the FA and LD. With the emergence of the FA we see an increase in the variances of all variables, which is marked in the case of output and investment. Variances increase further at first, as LD is introduced, but for complete LD, investment and net worth volatility are lower. We explore this phenomenon in our following discussion of impulse response functions. The combination of the FA and LD is a lethal cocktail for the welfare of households. Welfare loss increases sharply for high levels of LD with $\varphi>0.5$. The variance of the nominal interest rate also increases substantially with further implications for welfare when we impose the ZLB.

To summarize these results:

- Inflation, consumption, and output volatility worsen markedly as financial frictions in the form of the FA, and eventually LD, are introduced. However, TD, even when complete, does not worsen volatility except for the nominal interest rate.

- Full liability dollarization combined with the financial accelerator leads to levels of real and nominal volatility that are several times larger than those present in an economy without such features, for the same shocks. As a result, the expected welfare loss increases sharply for high levels of $\operatorname{LD}$ with $\varphi<0.5$.

- The central bank is more aggressive in its use of the nominal interest rate with both forms of dollarization. As a result, the variance of the nominal interest rate increases, and markedly so for LD. This has important further implications for welfare when we impose the interest rate zero lower bound. 
How do these volatilities match up to data on financially dollarized economies? Probably the most definitive and wide-ranging work on empirical issues on dollarization is due to Levy Yeyati (2006), who analyzes a unique database. His cross-sectional time series data reveals a positive correlation between dollarization and the standard deviation of growth rates, which is a feature of the penultimate row of table 5.2. Without liability dollarization, devaluations lead to countercyclical behavior and eventually restore the economy to equilibrium. In the presence of LD, the balance sheet effect ultimately leads to lower borrowing and capital formation, and lower growth on average coupled with increased variability. ${ }^{18}$

\subsubsection{Assessing the Impact of Key External and Internal Shocks}

In this section we study impulse responses for two selected shocks, which our earlier results have shown have important welfare implications: a technology shock $\left(a_{t}\right)$ and a shock to the country's external risk premium, $\boldsymbol{\epsilon}_{U I P, t}$. These are shown in figures 5.3 through 5.6, which concentrate on the baseline model (no frictions/dollarization) and model variants where dollarization/ frictions are most pernicious (models III and IVH). Although the analysis looks similar to Gilchrist (2003), it is in fact quite distinct in that here we are interested in comparing the transmission of shocks as frictions and dollarization increase, rather than in comparing the performance of flexible versus fixed exchange rates given frictions and liability dollarization.

To understand how the transmission of the shock changes for different levels of frictions and dollarization, we need first to take a step back and illustrate some of the mechanisms driving the real exchange rate, and the behavior of net worth of the wholesale firms sector.

Movements in the real exchange rate (and the related terms of trade) are critical for understanding our results. Linearization of the modified UIP condition (17) gives

$$
r e r_{t}=E_{t} r e r_{t+1}+E_{t}\left(r_{t}^{*}-r_{t}\right)-\delta_{r} b_{F, t}+\epsilon_{U I P, t},
$$

Solving (63) forward, in time we see that the real exchange rate is a sum of future expected real interest rate differentials with the ROW plus a term proportional to the sum of future expected net liabilities plus a sum of expected future shocks $\epsilon_{U I P, t}$. The real exchange will depreciate (a rise in $r e r_{t}$ ) if the sum of expected future interest rate differentials are positive and/or the sum of expected future net liabilities are positive and/or a positive shock to the risk premium, $\epsilon_{U I P, t}$ occurs.

Also crucial to the understanding of the effects of the FA and LD is the behavior of the net worth of the wholesale sector. In linearized form this is given by

18. However, Levy Yeyati (2006) is unable to pick up the balance sheet effects from the data. 


$$
\begin{aligned}
& n_{t}=\frac{\xi_{e}}{1+g}\left[\frac{1}{n_{k}} r_{t=1}^{k}+(1+\Theta)(1+R) n_{t-1}+\left(1-\frac{1}{n_{k}}\right)\right. \\
& \cdot\left[(1+R) \theta_{t-1}+(1+\Theta)\left(\varphi r_{t-1}+(1-\varphi)\left(r_{t-1}^{*}+(1+R)\left(\text { rer }_{t}-\text { rer }_{t-1}\right)\right]\right]\right.
\end{aligned}
$$

where the ex ante cost of capital is given by $r_{t-1}^{k}$. In (64) since leverage $1 / n_{k}>1$ we can see that net worth increases with the ex post return on capital at the beginning of period $t, r_{t-1}^{k}$, and decreases with the risk premium $\theta_{t-1}$ charged in period $t-1$ and the ex post cost of capital in home currency and dollars, $\varphi r_{t-1}+(1-\varphi)\left(r_{t-1}^{*}+(1+R)\left(r e r_{t}-r e r_{t-1}\right)\right)$, noting that $\left(r e r_{t}-r e r_{t-1}\right)$ is the real depreciation of the home currency. Starting at the steady state at $t=0$, from (64) at $t=1$ we have

$$
n_{1}=\frac{\xi_{e}}{1+g}\left[(1-\delta) q_{1}+\left(1-\frac{1}{n_{k}}\right)(1+\Theta)(1-\varphi)(1+R) r e r_{1}\right]
$$

Thus, net worth falls if Tobin's $\mathrm{Q}$ falls and if some borrowing is in dollars $(\varphi<1)$. We see also that a depreciation of the real exchange rate $\left(\right.$ rer $\left._{1}>0\right)$ brings about a further drop in net worth. However, an appreciation of the real exchange rate $\left(\mathrm{rer}_{1}<0\right)$ will offset the drop in net worth. Output falls through two channels: first, a drop in Tobin's $Q$ and a subsequent fall in investment demand and, second, through a reduction in consumption by entrepreneurs.

\section{Total Factor Productivity (TFP) Shock}

Figures 5.3 and 5.4 illustrate the transmission channels in the model under optimal monetary policy in response to a negative 1 percent shock to total factor productivity. Because TD does not result in big differences in volatilities, we focus on only three variants: the baseline model with no TD nor FA, the model with a FA, and the model with both the FA and a high degree of LD. For all three models we have the following broad features: the shocks result in an immediate fall in consumption, output, and investment, a tightening of optimal monetary policy with a rise in the nominal and expected real interest rate, an appreciation of the real exchange rate ( $\mathrm{rer}_{t}$ falls), a fall in the terms of trade $\left(p_{F, t}-p_{H, t}=\tau_{t}=\operatorname{rer}_{t} / \omega\right)$, a trade deficit, and a decline in net future assets. Investment falls because Tobin's Q (defined in the graphs as the real market price of capital relative to the price of capital goods, $\left.q_{t}^{k}=q_{t}-p_{I, t}+p_{t}\right)$ falls, which in turn responds to an anticipated future fall in profits relative to the cost of capital. With the FA switched on, the fall in Tobin's Q measured relative to the price of capital relative to the consumption good, $q_{t}$, causes net worth to fall, which in turn causes the external financing premium facing firms, $\theta_{t}$, to rise. This exacerbates the increase in the cost of capital and Tobin's Q, and therefore investment, falls further. This is the familiar effect of a FA highlighted, for example, in Gertler, Gilchrist, and Natalucci (2003). 

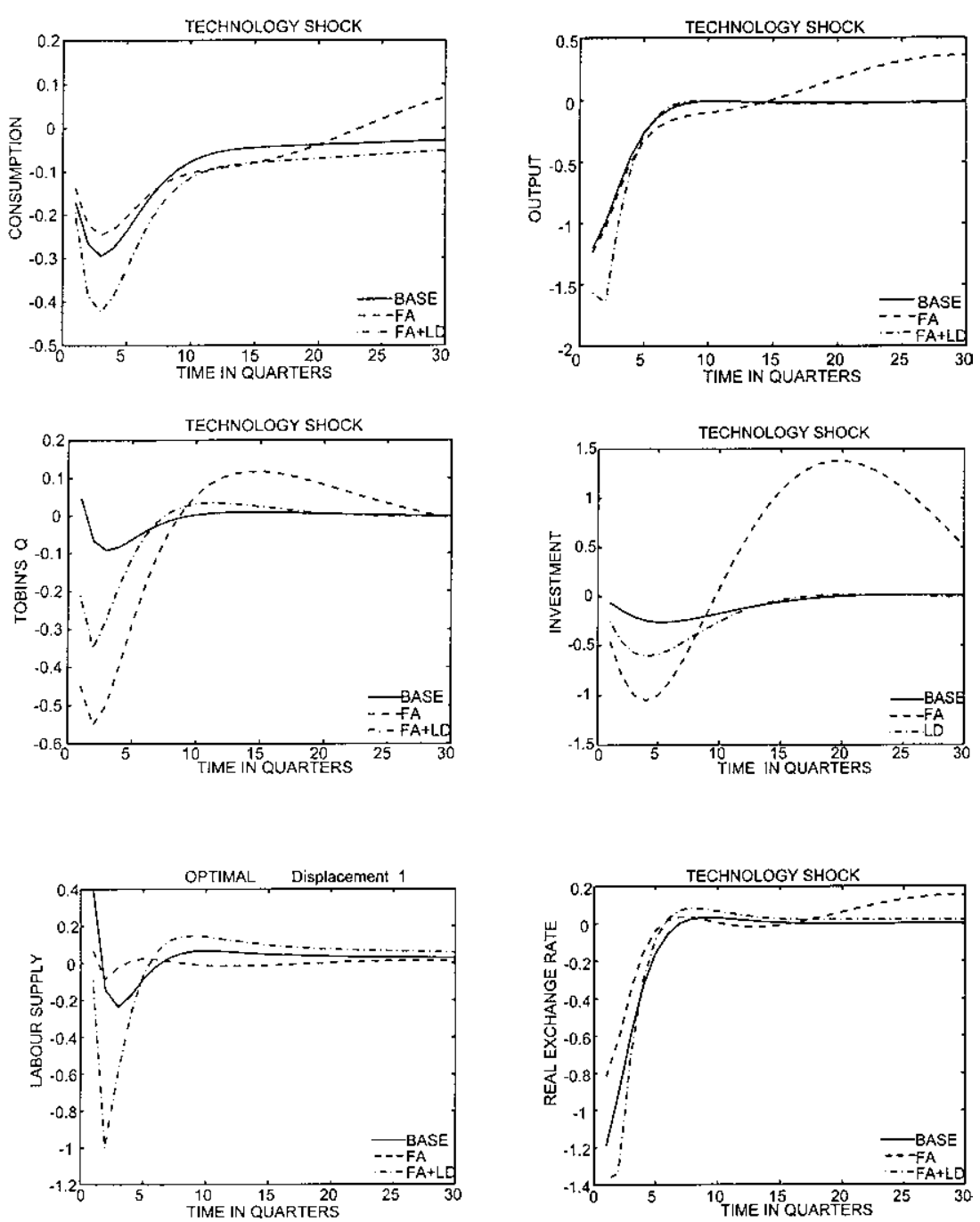

Fig. 5.3 Responses to a technology shock under optimal monetary policy

Now consider the FA plus LD where for the graphs we assume all borrowing by firms is in dollars $(\varphi=0)$. In this case, net worth and investment fall by far less, and net worth relative to the value of capital hardly changes, as can be seen from movements in the external risk premium. Why is this? The reason is the appreciation of the exchange rate which (from [65] with $\varphi<1$ ) offsets the fall in net worth brought about by the fall in Tobin's Q. The policymaker responds to this by tightening more monetary condi- 

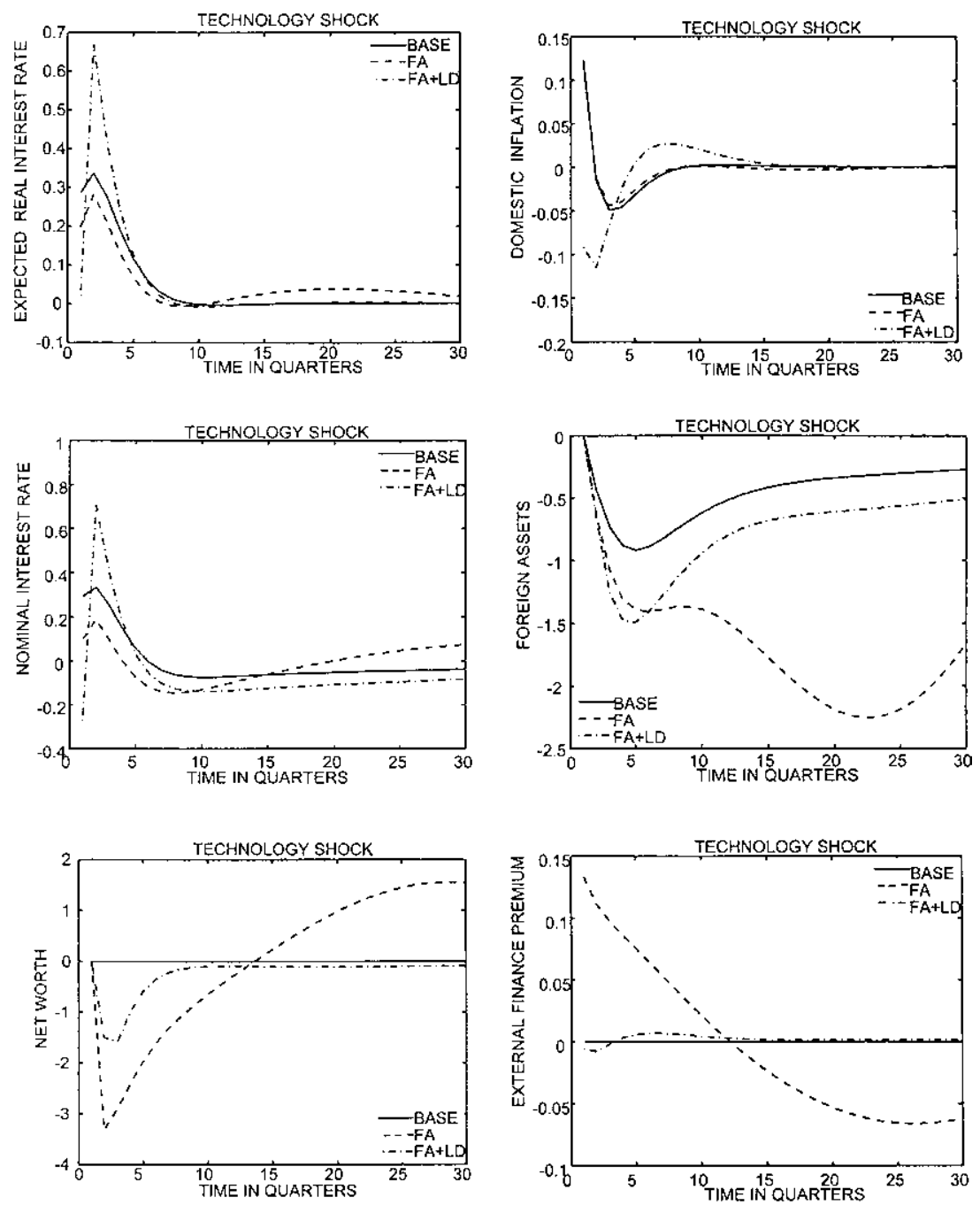

Fig. 5.4 Responses to a technology shock under optimal monetary policy

tions, so that the expected real interest rate rises relative to what happens in a model without LD. Thus, the presence of LD induces a stronger monetary intervention particularly in the short run. Another way to explain this is by saying that monetary policy is less effective under LD, other things equal, because the output gap channel of monetary transmission is weaker (since borrowing is partly in dollars, and so the cost of capital is less directly affected by changes in the interest rate), while the exchange rate channel is 
stronger (because under LD changes in the exchange rate generate balance sheet effects in addition to affecting net trade). As a result, the central bank uses the exchange rate more intensely as a stabilizing device, by creating domestic relative to abroad interest rate differentials. For big enough TFP shocks, however, use of the exchange rate channel to minimize "financialaccelerated" output fluctuations may clash with the objective of keeping inflation within a certain range. As indicated by the figure, it takes much longer for domestic inflation to return to target in a model with FA + LD than in a model without frictions or dollarization.

\section{Country External Risk Premium Shock}

Next, in figures 5.5 and 5.6, we turn to a 1 percent to the domestic country's external risk premium $\epsilon_{U I P t}$ in (63). Now the real exchange rate depreciates instead of appreciating, as was the case with the technology shock. The responses of all three variants of the model are again broadly similar, implying a drop in output, consumption, investment, a fall in Tobin's Q, a tightening of monetary policy, and a fall in net worth. The real depreciation of the exchange rate leads to a trade surplus and an accumulation of foreign assets. The effect of the FA on net worth, the external risk premium, and investment is pretty much the same as for the previous simulations. But when we combine the FA with LD an important difference emerges. Since the real exchange rate now depreciates instead of appreciating, the initial fall in net worth is exacerbated rather than attenuated by balance sheet effects, and the external risk premium rises by more. Monetary policy is tightened by more than in the TFP shock case, so the depreciation is short-lived because the interest rate differential relative to abroad is rapidly closed, and is eventually reversed, turning into an appreciation. With $\mathrm{LD}$, the appreciation that follows the monetary tightening triggers a further balance sheet effect that has the effect of returning net worth back to its steady state faster than in the FA without LD. Thus, LD has a longstabilizing effect on movements in net worth. Given that the external risk premium also returns faster to its equilibrium, forward-looking investment under LD behaves similarly to investment in the baseline, frictionless model. The immediate implication is that output returns faster to potential and generally contracts by less under FA + LD than in the baseline model with no frictions or in the FA-only model, a result that contrasts with the finding in Gertler, Gilchrist, and Natalucci (2003) using simple nonoptimized rules. The other key finding is that, once again, although FA and LD imply similar responses of investment, LD tends to make monetary policy more aggressive. Exactly as in the case of the TFP shock, this is optimal in thatunder LD - the monetary authority can take advantage of the interest rate/ exchange rate UIP channel to affect the exchange rate, and this way bring net worth and investment (and hence output and inflation) faster back to equilibrium. 

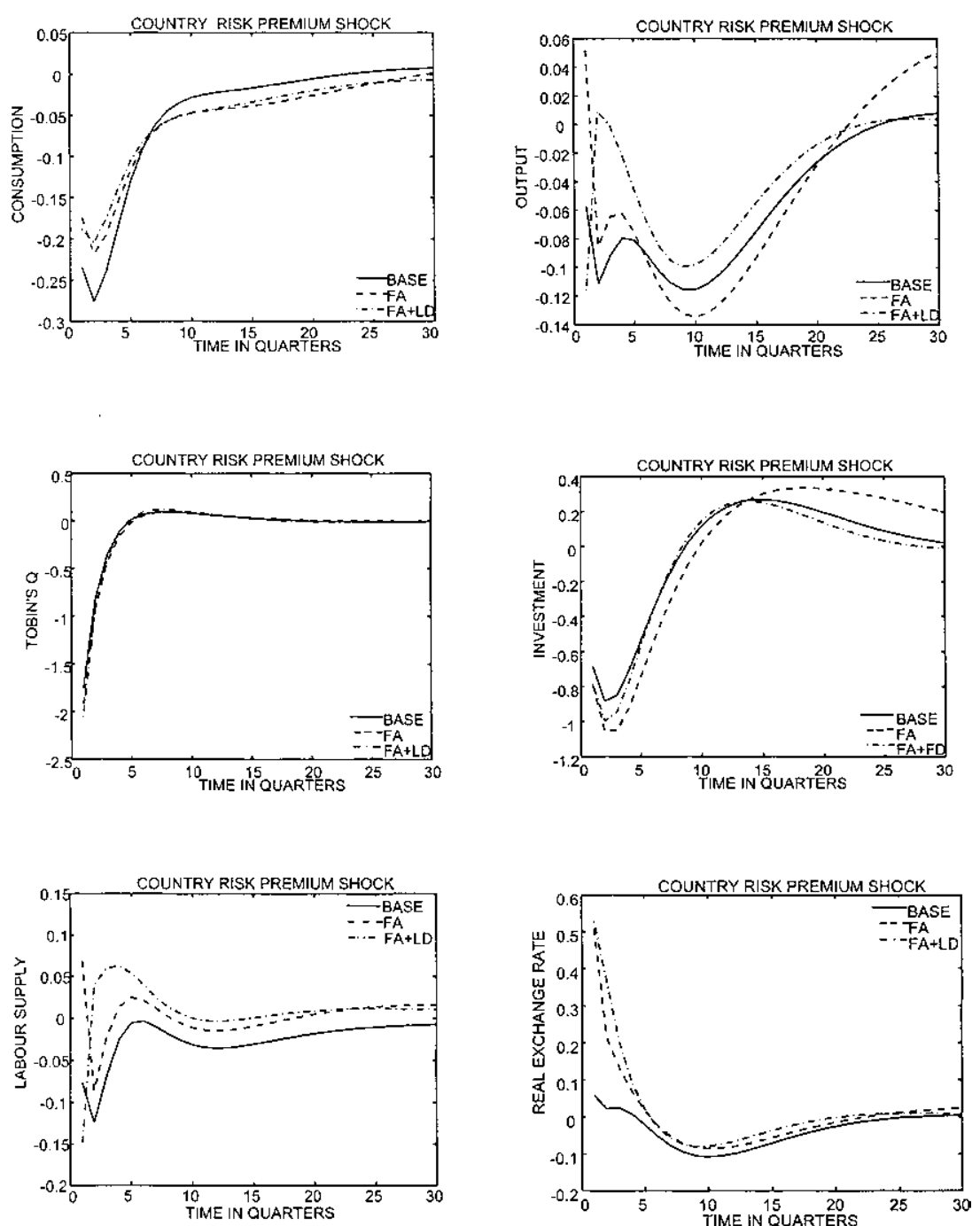

Fig. 5.5 Responses to a UIP shock under optimal monetary policy

\subsection{The Fixed Exchange Rate Regime and Optimal Rules}

What is left to understand now is what is hence the optimal degree of exchange rate stabilization (given inflation stabilization) in economies with frictions and dollarization. To this end we proceed to search simple optimized rules that maximize a welfare criterion based on households' utility under financial frictions and dollarization. We focus on the three regimes described previously, namely FIX, FLEX, and HYB. For the latter two 

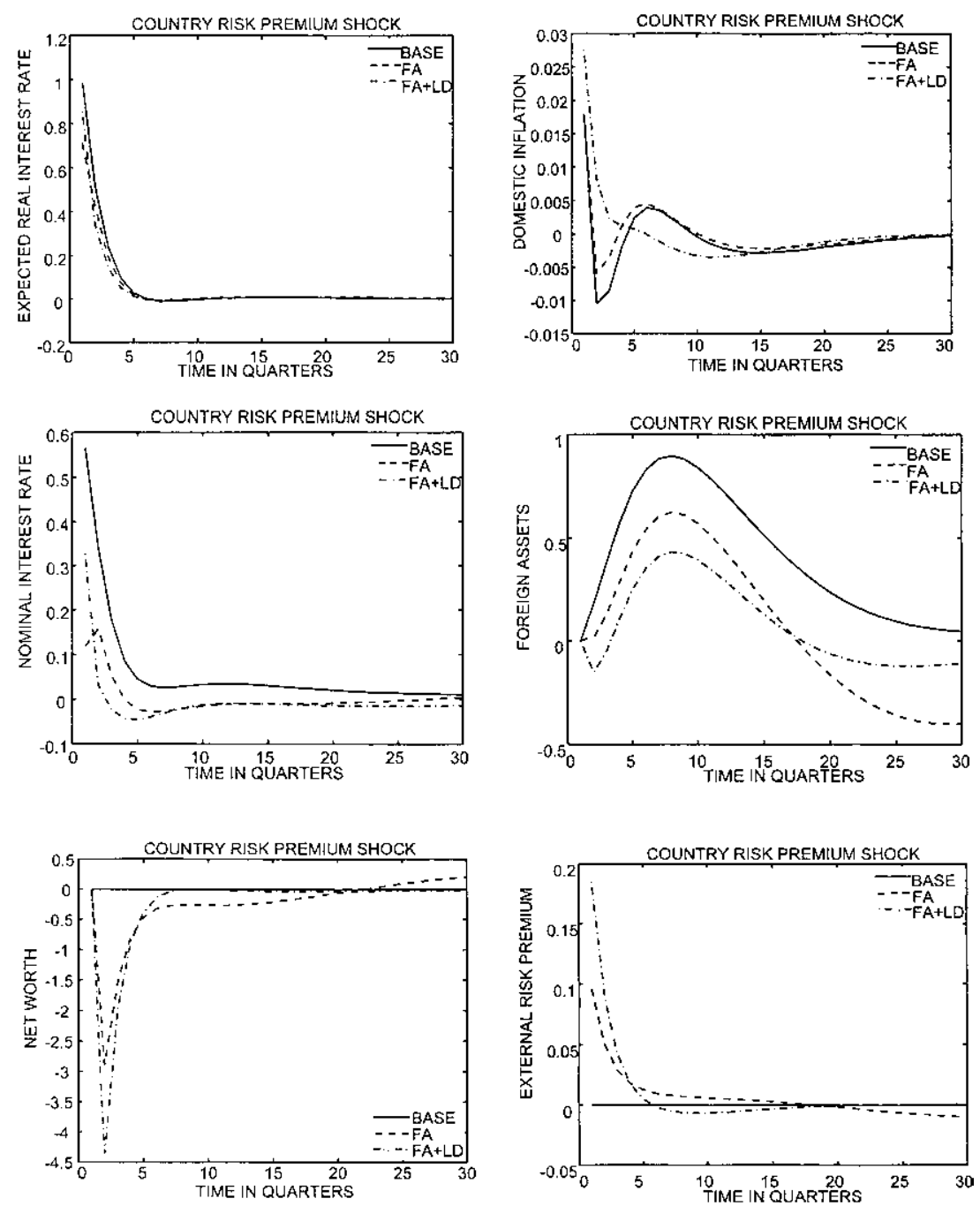

Fig. 5.6 Responses to a UIP shock under optimal monetary policy

regimes we compute optimized rules that minimize the expected welfare loss with respect to the feedback parameters $\rho \in[0,1], \pi_{\theta}$, and $\pi_{s}$. We restrict our search to $\pi_{\theta} \in[1,5]$ : the lower bound ensures the rule satisfies the Taylor principle and the imposed upper bound avoids large initial jumps in the nominal interest rate.

We search simple rules that are optimal for four model variants (where in model II we set $a=1 / 2$; i.e., moderate TD, in model IV we set $\varphi=0.75$; i.e., a moderate LD). 
Table 5.3

Optimized rules

\begin{tabular}{lllll}
\hline Rule & $\rho$ & $\theta_{\pi}$ & $\theta_{y}$ & \multicolumn{1}{c}{$\theta_{s}$} \\
\hline FLEX(D): Model I & 1.0 & 5.0 & 0.32 & 0 \\
FLEX(C): Model I & 1.0 & 5.0 & 0.016 & 0 \\
HYB: Model I & 1.0 & 5.0 & 0.29 & 0.025 \\
FLEX(D): Model II & 1.0 & 5.0 & 0.25 & 0 \\
FLEX(C): Model II & 0.82 & 5.0 & 0.016 & 0 \\
HYB: Model II & 1.0 & 5.0 & 0.22 & 0.03 \\
FLEX(D): Model III & 0.95 & 5.0 & 0.44 & 0 \\
FLEX(C): Model III & 0.62 & 5.0 & 0.011 & 0 \\
HYB: Model III & 0.95 & 5.0 & 0.44 & 0 \\
FLEX(D): Model IV & 0.91 & 5.0 & 0.34 & 0 \\
FLEX(C): Model IV & 0.72 & 5.0 & 0.069 & 0 \\
HYB: Model IV & 0.91 & 5.0 & 0.34 & 0 \\
\hline
\end{tabular}

Table 5.3 provides the parameter values that optimize the FLEX and HYB rules in these four cases. ${ }^{19}$ Tables 5.4 through 5.7 report variances from simulating each model variant under all shocks for the corresponding simple optimized FIX, FLEX, and HYB rule. ${ }^{20} \mathrm{~A}$ joint read of these tables points to some interesting results.

- Responding directly to the exchange rate, in addition to inflation and output growth, is not optimal under liability dollarization or in the presence of financial frictions (FA in particular): the optimal feedback from the exchange rate is zero, or close to zero across all models. Thus, central banks in countries with these features should not attempt to manage the exchange rate nor, more generally, attempt to balance inflation and exchange rate stability objectives. This finding restates the Gilchrist (2003) result obtained using simple nonoptimized rules. The reason is clear: financial dollarization weakens the output gap channel and strengthens the exchange rate channel of monetary policy transmission - which gets activated through the UIP via interest rate changesbecause, in this case, the cost of capital on which output (and inflation) depend are a function of both the real interest rate and the real exchange rate. Because under financial dollarization exchange rate becomes the key adjustment variable, changes in it are necessary to stabilize inflation by attenuating the financial accelerator effects. Thus, fixing the exchange rate or reducing its volatility limits the ability of the central bank to enact stabilizing monetary interventions, and forces it to larger interest rate gyrations instead. These induce larger welfare losses both because the central bank now forgoes the possibility to use the exchange rate to

19. Note there is no "optimal" FIX regime since the parameter $\theta_{s}$ is simply set at a value sufficiently high to ensure a fixed exchange rate.

20 . We omit to report results on model $\mathrm{V}$ for the reasons described previously. 


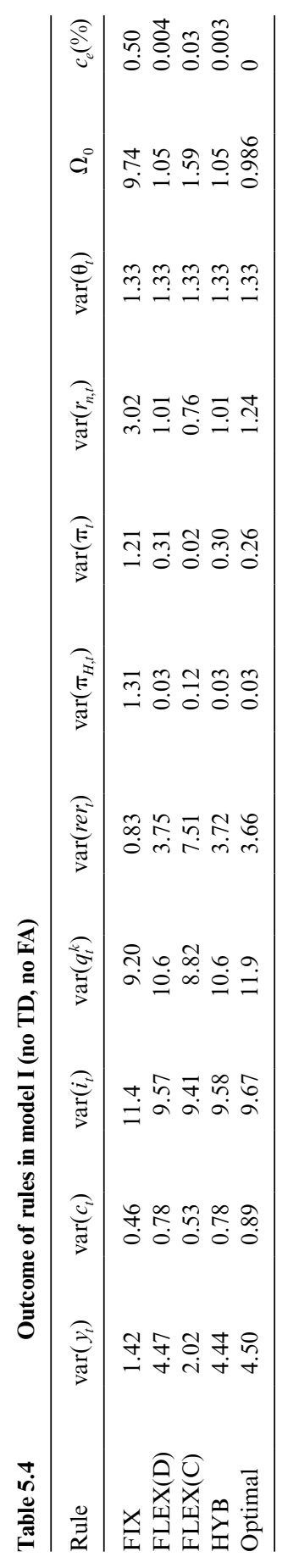




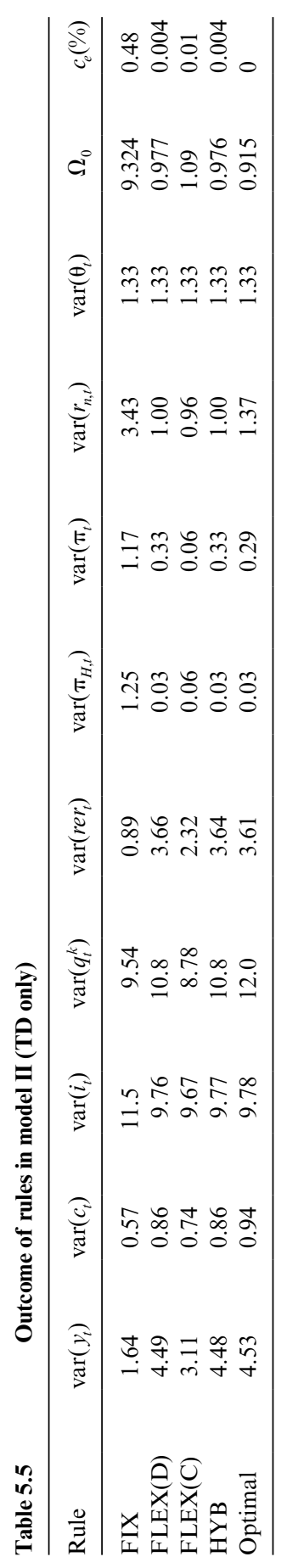




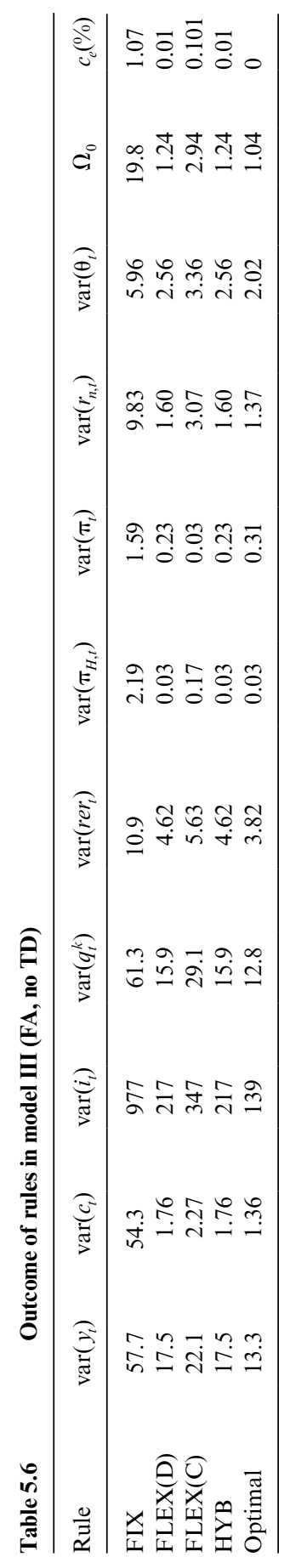




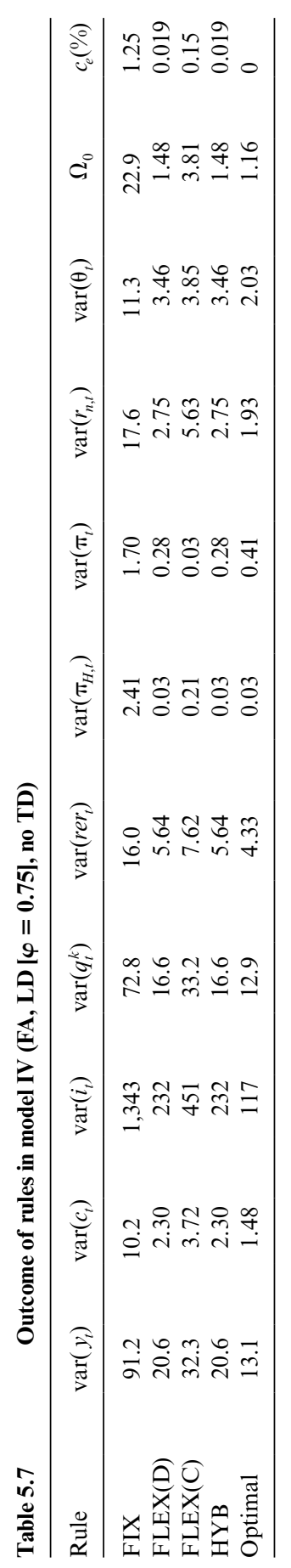


undo financial accelerator effects and because aggressive changes in the interest rate generate adverse balance sheet effects at home by raising strongly the cost of capital, which in turn affects net worth and output.

- Responding indirectly to the exchange rate by choosing a consumer price rather than a domestic price inflation target, regime FLEX $(C)$ is also severely suboptimal. The reasons for this are broadly the same as those for the failure of HYB to improve on FLEX(D).

- With flexible exchange rates, under FA + LD policy tends to be more aggressive, other things equal, with larger gyrations of the interest rate than under no frictions/dollarization. Adding an explicit feedback response to the exchange rate instills yet additional volatility to the interest rate with negative repercussions on all macrovariables (table 5.7) and a larger welfare loss. In the extreme case of exchange rate fixity (FIX) results are disastrous.

- The optimal parameters in our simple rules are similar across models, which means that a domestic inflation feedback rule with an added feedback for output is a robust rule with respect to any model uncertainty regarding financial frictions. Emerging market central banks do not have to significantly differentiate the way the monetary conditions are set from the way these are set in advanced, relatively frictionless economies.

- Finally, our results indicate that smoothing interest rate changes is desirable independently of the frictions/dollarization features of the economy - and indeed, integral rules always outperform proportional rules. ${ }^{21}$

Two questions remain. Given that there is little or no scope for targeting the nominal exchange rate, what is the welfare cost of maintaining a fixed rate? Second, the Taylor-type rules are only optimal given the constraints implied by the particular inflation and output growth targets, but is suboptimal compared with the fully optimal commitment rule. What, then, is the welfare cost of restricting rules in this way? Tables 5.4 through 5.8 provide answers to these questions. These tables provide outcomes in terms of unconditional variances of key variables where the maximized welfare losses $\Omega_{0}$ are provided and compared with those for the optimal commitment policy. In the final column we provide the percentage consumption equivalent welfare loss compared with the optimal policy derived in appendix E and given by ${ }^{22}$

$$
c_{e}=\frac{\Omega_{0}^{i}-\Omega_{0}^{O P T}}{(1-\rho)\left(1-h_{C}\right) c_{y}} \times 10^{-2}, i=\operatorname{FIX}, \operatorname{FLEX}(\mathrm{D}), \operatorname{FLEX}(\mathrm{C}) .
$$

A number of noteworthy points emerge from these results on welfare costs. First, the fixed exchange rate constraint imposes a cost in terms of a

21. As is shown in Batini, Levine, and Pearlman (2004) in an open economy context, interest rate smoothing is also desirable because it allows the rule to feedback strongly from the interest rate target without falling foul of determinacy.

22. Note that all welfare losses have been normalized by the terms $1-\beta / F Y$ - see appendix E. In addition, all variances are in percent ${ }^{2}$, so that $c_{e}$ is in percent form. 
permanent consumption equivalent of 0.48 through 0.50 percent for models I and II, rising to 1.25 percent in model IV. The introduction of the FA sees these consumption costs increase significantly and then rise again with the introduction of the LD at the moderate level of $\varphi=0.75$ (meaning a quarter of the firms' borrowing is in dollars). Second, optimized domestic inflation Taylor-type rules mimic the fully optimal rule closely with a very small consumption equivalent loss. The latter rises with the introduction of the FA and again with LD, but remains small. So not only are optimized rules of this simple rule robust, they are only slightly suboptimal. Third, CPI inflation rules, however, impose far higher costs from 0.03 to 0.15 percent as one progresses from model I to model IV.

In one respect, the consumption equivalent costs reported up to now are misleading, especially for the FIX regime. The reason for this is to be seen for the unconditional variances reported in these, which are very large in the case of FIX and rise for all regimes when we introduce the FA and then LD. Such high variances imply that the interest rate under these optimized or optimal rules will hit the interest rate zero lower bound frequently. ${ }^{23}$ The next section addresses this design fault in the rules.

\subsection{Imposing the Nominal Interest Rate Zero Lower Bound}

We now modify our interest rate rules to approximately impose an interest rate ZLB so that this event hardly ever occurs. Although so far only a few emerging market countries have experienced deflationary episodes (Peru and Israel in 2007 are examples of this), most inflation targeting emerging market countries have chosen low single digit inflation targets (see IMF [2005]), which makes the design of rules robust to ZLB problems germane. As in Woodford (2003, chapter 6), the ZLB constraint is implemented by modifying the single period welfare loss (62) to $L_{t}+w_{r} r_{n, t}^{2}$. Then following Levine, McAdam, and Pearlman (2007), the policymaker's optimization problem is to choose $w_{r}$ and the unconditional distribution for $r_{n, t}$ (characterized by the steady-state variance) shifted to the right about a new nonzero steady state inflation rate and a higher nominal interest rate, such that the probability, $p$, of the interest rate hitting the lower bound is very low. This is implemented by calibrating the weight $w_{r}$ for each of our policy rules so that $z_{0}(p) \sigma_{r}<R_{n}$, where $z_{0}(p)$ is the critical value of a standard normally distributed variable $Z$ such that $\operatorname{prob}\left(Z \leq z_{0}\right)=p, R_{n}=1 /\left(\beta\left(1+g_{u_{\mathrm{c}}}\right)-1+\pi^{*}\right.$ is the steady-state nominal interest rate, $\sigma_{r}^{2}=\operatorname{var}\left(r_{n}\right)$ is the unconditional variance, and $\pi^{*}$ is the new steady-state inflation rate. Given $\sigma_{r}$, the steady-state positive inflation rate that will ensure $r_{n, t} \geq 0$ with probability $1-p$ is given by ${ }^{24}$ 
Table 5.8

Optimal commitment with a nominal interest rate ZLB (Model IV with $\varphi$ $=0.75$ )

\begin{tabular}{lllllll}
\hline$w_{r}$ & $\sigma_{r}^{2}$ & $\tilde{\Omega}_{0}\left(w_{r}\right)$ & $\tilde{\Omega}_{0}(0)$ & $\pi^{*}$ & $\bar{\Omega}_{0}(0)$ & $\Omega_{0}(0)$ \\
\hline 0 & 1.93 & 1.156 & 1.156 & 0.46 & 0.476 & 1.632 \\
0.1 & 1.72 & 1.231 & 1.160 & 0.22 & 0.109 & 1.269 \\
0.2 & 1.58 & 1.300 & 1.169 & 0.06 & 0.008 & 1.177 \\
0.3 & 1.47 & 1.363 & 1.181 & 0 & 0 & 1.181 \\
0.4 & 1.38 & 1.422 & 1.194 & 0 & 0 & 1.194 \\
\hline
\end{tabular}

Notes: $\pi^{*}=\max \left[z_{0}(p) \sigma_{r}-\left(1 /\left(\beta\left(1+g_{u_{c}}\right)-1\right) \times 100,0\right]=\max \left[3.00 \sigma_{r}-3.71,0\right]\right.$ with $p=0.001$ probability of hitting the zero lower bound and $\beta=0.99, g_{u_{c}}=-0.26$.

$\bar{\Omega}_{0}(0)=1 / 2 w_{\pi} \pi^{* 2}=2.248 \pi^{* 2} ; \Omega_{0}(0)=\tilde{\Omega}_{0}(0)+\bar{\Omega}_{0}(0)$.

$$
\pi^{*}=\max \left[z_{0}(p) \sigma_{r}-\left(\frac{1}{\beta\left(1+g_{u_{\mathrm{c}}}\right)}-1\right) \times 100,0\right] .
$$

In our linear quadratic framework we can write the intertemporal expected welfare loss at time $t=0$ as the sum of stochastic and deterministic components, $\Omega_{0}=\tilde{\Omega}_{0}+\bar{\Omega}_{0}$. Note that $\bar{\Omega}_{0}$ incorporates in principle the new steady-state values of all the variables; however, the NK Phillips curve being almost vertical, the main extra term comes from the $\pi^{2}$ term in equation (E.32). By increasing $w_{r}$ we can lower $\sigma_{r}$, thereby decreasing $\pi^{*}$ and reducing the deterministic component, but at the expense of increasing the stochastic component of the welfare loss. By exploiting this trade-off, we then arrive at the optimal policy that, in the vicinity of the steady state, imposes the ZLB constraint, $r_{t} \geq 0$, with probability $1-p$.

Tables 5.8 and 5.9 show the results of this optimization procedure for the optimal commitment rules and the optimized simple rules, respectively, for the case of model IV. We choose $p=0.001$. Given $w_{r}$, denote the expected intertemporal loss (stochastic plus deterministic components) at time $t=0$ by $\Omega_{0}\left(w_{r}\right)$. This includes a term penalizing the variance of the interest rate that does not contribute to utility loss as such, but rather represents the interest rate lower bound constraint. Actual utility, found by subtracting the interest rate term, is given by $\Omega_{0}(0)$. The steady-state inflation rate, $\pi^{*}$, that will ensure the lower bound is reached only with probability $p=0.001$, and is computed using (67). Given $\pi^{*}$, we can then evaluate the deterministic component of the welfare loss, $\bar{\Omega}_{0}$. Because in the new steady state the real interest rate is unchanged, the steady state involving real variables are also unchanged, so from (62) we can write $\bar{\Omega}_{0}(0)=w_{\pi} \pi^{* 2}$. Both the ex ante optimal and the optimal time consistent deterministic welfare loss that guide

Woodford [2003]) in effect replaces it with a nominal interest rate variability constraint, which ensures the ZLB is hardly ever hit. By contrast, the work of a number of authors - including Adam and Billi (2007), Coenen and Wieland (2003), Eggertsson and Woodford (2003), and Eggertsson (2006) - study optimal monetary policy with commitment in the face of a nonlinear constraint $i_{t} \geq 0$, which allows for frequent episodes of liquidity traps in the form of $i_{t}=0$. 


\begin{tabular}{|c|c|c|c|c|c|c|c|}
\hline \multirow[b]{2}{*}{$w_{r}$} & \multicolumn{7}{|c|}{ Model IV } \\
\hline & {$\left[\rho, \theta_{\pi}, \theta_{\Delta y}\right]$} & $\operatorname{var}\left(r_{n, t}\right)$ & $\tilde{\Omega}_{0}\left(w_{r}\right)$ & $\tilde{\Omega}_{0}(0)$ & $\pi^{*}$ & $\bar{\Omega}_{0}(0)$ & $\Omega_{0}(0)$ \\
\hline \multicolumn{8}{|c|}{$A F L E X(D)$} \\
\hline 0 & {$\left[\begin{array}{llll}0.91 & 5.0 & 0.39\end{array}\right]$} & 2.75 & 1.48 & 1.48 & 2.53 & 14.39 & 15.87 \\
\hline 0.5 & [ $\left.\begin{array}{llll}1.0 & 5.0 & 0.54\end{array}\right]$ & 2.52 & 1.98 & 1.49 & 2.32 & 12.10 & 13.59 \\
\hline 1 & {$\left[\begin{array}{llll}1.0 & 5.0 & 0.64\end{array}\right]$} & 2.44 & 2.47 & 1.51 & 2.25 & 11.38 & 12.89 \\
\hline 2 & {$\left[\begin{array}{lll}1.0 & 5.0 & 0.78\end{array}\right]$} & 2.36 & 3.40 & 1.55 & 2.17 & 10.59 & 12.14 \\
\hline 3 & {$\left[\begin{array}{llll}1.0 & 5.0 & 0.87\end{array}\right]$} & 2.32 & 4.32 & 1.59 & 2.13 & 10.20 & 11.79 \\
\hline 4 & {$\left[\begin{array}{llll}1.0 & 5.0 & 0.94\end{array}\right]$} & 2.30 & 5.22 & 1.61 & 2.11 & 10.01 & 11.62 \\
\hline 5 & {$\left[\begin{array}{llll}1.0 & 5.0 & 0.99\end{array}\right]$} & 2.28 & 6.13 & 1.63 & 2.09 & 9.82 & 11.45 \\
\hline 10 & {$\left[\begin{array}{llll}1.0 & 5.0 & 1.13\end{array}\right]$} & 2.26 & 10.6 & 1.70 & 2.07 & 9.63 & 11.33 \\
\hline 20 & {$\left[\begin{array}{llll}1.0 & 5.0 & 1.24\end{array}\right]$} & 2.24 & 19.48 & 1.75 & 2.05 & 9.45 & 11.20 \\
\hline 50 & {$\left[\begin{array}{lll}1.0 & 5.0 & 1.34\end{array}\right]$} & 2.24 & 46.02 & 1.80 & 2.05 & 9.45 & 11.25 \\
\hline \multicolumn{8}{|c|}{$B F L E X(C)$} \\
\hline 0 & [ $\left.\begin{array}{llll}0.0 & 19.90 & 1.066\end{array}\right]$ & 5.21 & 3.67 & 3.67 & 3.14 & 22.16 & 25.83 \\
\hline 5 & {$\left[\begin{array}{lll}1.0 & 15.66 & 5.0\end{array}\right]$} & 4.04 & 11.73 & 3.99 & 2.32 & 12.10 & 16.09 \\
\hline 10 & {$\left[\begin{array}{lll}1.0 & 12.48 & 5.0\end{array}\right]$} & 3.99 & 19.38 & 4.15 & 2.28 & 11.68 & 15.83 \\
\hline 15 & {$\left[\begin{array}{llll}1.0 & 11.27 & 5.0\end{array}\right]$} & 3.97 & 26.96 & 4.24 & 2.27 & 11.58 & 15.82 \\
\hline 20 & {$\left[\begin{array}{lll}1.0 & 10.61 & 5.0\end{array}\right]$} & 3.97 & 34.43 & 4.30 & 2.27 & 11.58 & 15.88 \\
\hline
\end{tabular}

the economy from a zero inflation steady state to $\pi=\pi^{*}$ differ from $\bar{\Omega}_{0}(0)$ (but not by much because the steady-state contributions by far outweigh the transitional one).

Table 5.10 summarizes the outcomes of optimized simple rules and the optimal rule with a ZLB approximately imposed in model IV. Comparing the last columns of tables 5.10 and 5.7 we can see that ZLB considerations create a substantial consumption equivalent loss for the fixed exchange rate, $c_{e}$, and smaller but significant one for the regimes FLEX(D) and FLEX(C), the latter being almost double the former. Under the FE there is no scope for trading off the variance of the nominal exchange rate with other macroeconomic variances that impact on welfare. Thus, the only way of reducing the probability of hitting the lower bound is to increase the steady-state inflation rate, which rises to 9 percent per quarter. This imposes a very large welfare loss, reflected in $c_{e}=11.4$ percent. ${ }^{25}$ For the Taylor rules there are some tradeoffs between the variance of the nominal interest rate and the variances of inflation, consumption, and other variables impacting on welfare. Thus, for the optimized rule under a ZLB the variance of the nominal interest rate falls from 2.75 (percent) $^{2}$ to 2.24 (percent) ${ }^{2}$ as $w_{r}$ increases, at a steady-state inflation cost of 2.05 percent per quarter. The consumption equivalent loss

25. However, full dollarization, for example via a currency board, would result in $r_{n, t}=r_{n, t}^{*}$ and the ZLB then ceases to be a concern for the domestic country. This would still leave a significant welfare loss for the FIX regime (equal to that reported in table 5.7) of $c_{e}=1.25$ percent. We are grateful to Marc Giannoni for pointing this out. 
Table 5.10

Summary of welfare outcome of rules with a nominal interest rate ZLB imposed

\begin{tabular}{lcccrcc}
\hline & \multicolumn{6}{c}{ Model IV } \\
\cline { 2 - 7 } Rule & $\operatorname{var}\left(r_{n, t}\right)$ & $\pi^{*}$ & $\tilde{\Omega}_{0}(0)$ & $\bar{\Omega}_{0}(0)$ & $\Omega_{0}(0)$ & $c_{e}(\%)$ \\
\hline FIX & 17.6 & 8.88 & 22.9 & 177 & 200 & 11.4 \\
FLEX(D) & 2.24 & 2.05 & 1.75 & 9.45 & 11.2 & 0.57 \\
FLEX(C) & 3.97 & 2.27 & 4.24 & 11.58 & 11.82 & 0.83 \\
Optimal & 1.58 & 0.06 & 1.17 & 0.01 & 1.18 & 0 \\
\hline
\end{tabular}

Note: $c_{e}$ is the consumption equivalent welfare loss compared with the optimal policy given by $c_{e}=\left(\Omega^{i}(0)-\Omega^{O P T}(0)\right) /\left((1-\varrho)\left(1-h_{C}\right) c_{y}\right) \times 10^{-2}, i=\mathrm{FE}$, Taylor.

of the Taylor rules rises from 0.019 percent without ZLB concerns to 0.57 percent for $\operatorname{FLEX}(\mathrm{D})$ and 0.83 percent for $\operatorname{FLEX}(\mathrm{C})$, with such concerns.

\subsection{Conclusions}

Three clear results emerge from our analysis: first, given our calibration, the financial accelerator has a much larger impact on the performance of the optimized fixed exchange rate, Taylor, and hybrid interest rate rules than the presence of transactions dollarization. In particular, the costs of a fixed exchange rate regime rises significantly. Second, the introduction of liability dollarization alongside the financial accelerator increases these costs further. Finally, the zero lower bound constraint on the interest rate substantially increases the welfare cost of both the fixed exchange rate constraint, and restricts policy to an optimized Taylor, as opposed to a fully optimal monetary policy rule.

The message for monetary policymakers in emerging market economies struggling with frictions and dollarization is: do not try to achieve a double inflation exchange rate objectives, since this can backfire and lead to larger losses than commonly believed. You should fear to fix, not fear to float! Furthermore, central banks should not implicitly target the exchange rate by choosing a CPI rather than domestic price inflation target. Finally, the zero lower bound constraint on the interest rate substantially increases the welfare cost of the fixed exchange rate constraint, and restricts policy to an optimized flexible exchange rate Taylor-type rule, as opposed to a fully optimal monetary policy rule. As usual, central banks will have to carefully trade off in setting policy in a simple and monitorable way, with the costs of incurring in welfare losses from the higher risk of hitting the zero bound.

All our numerical results of course depend on both our choice of calibration and aspects of the modeling. On the former, while some experimentation suggests that the qualitative results should be robust with respect to a reasonable choice of alternatives, this will not be necessarily true of our quantitative findings on the welfare costs of various regimes. This suggests 
that future research could be usefully directed at a systems estimation of the model using Bayesian maximum likelihood methods now popular in the DSGE literature. ${ }^{26}$ Nor can we assert that our results would withstand significant changes to the model, such as the introduction of a large commodity exporting sector (e.g., copper or oil) with prices fixed to the dollar and a consequent large imported share of consumables. Again, this suggests an item for future research.

\section{Appendix A}

\section{The Steady State}

The BGP zero inflation steady-state balanced growth path with consumption, wholesale output, the wage and capital stock growing at a rate $g$ per period, must satisfy

$$
\begin{aligned}
& \frac{\bar{K}_{t+1}}{\bar{K}_{t}}=\frac{\bar{Y}_{t+1}}{\bar{Y}_{t}}=\frac{\bar{C}_{t+1}}{\bar{C}_{t}}=\frac{\bar{W}_{t+1}}{\bar{W}_{t}}=1+g \\
& \frac{\bar{A}_{t+1}}{\bar{A}_{t}}=1+g(1-\alpha) .
\end{aligned}
$$

Since there are no investment adjustment costs at the steady state, it follows that

$$
\bar{K}_{t+1}=(1-\delta) \bar{K}_{t}+\bar{I}_{t} .
$$

It follows from (A1) that

$$
\bar{I}_{t}=(g+\delta) \bar{K}_{t},
$$

and hence, the previous assumptions regarding $\Phi(\cdot)$ become $\Phi(g+\delta)=g$ $+\delta$ and $\Phi^{\prime}(g+\delta)=1$.

In what follows we denote the trended steady state of $X_{t}$ by $X$. Then the rest of the steady state is given by

$$
\begin{aligned}
C_{H} & =\mathrm{w}\left(\frac{P_{H}}{P}\right)^{-\mu} C \\
C_{F} & =(1-\mathrm{w})\left(\frac{P_{F}}{P}\right)^{-\mu} C \\
P & =\left[\mathrm{w} P_{H}^{1-\mu}+(1-\mathrm{w}) P_{F}^{1-\mu}\right]^{1 /(1-\mu)}
\end{aligned}
$$

26. Castillo, Montoro, and Tuesta (2006) provides a promising first attempt at estimating a small open economy model, with many of the features of found in our chapter, using data for Peru. 
(A8)

$$
\begin{aligned}
\frac{W}{P} & =-\frac{1}{1-(1 / \eta)} \frac{U_{L}}{U_{C}} \\
1 & =\beta\left(1+R_{n}\right)\left(1+g_{u_{\mathrm{c}}}\right)=\beta(1+R)\left(1+g_{u_{\mathrm{c}}}\right),
\end{aligned}
$$

where $g_{u_{\mathrm{c}}}$ is the growth rate of the marginal utility of consumption in the steady state given by

$$
g_{u_{\mathrm{c}}}=(1+g)^{(1-\varrho)(1-\sigma)-1}-1
$$

and

$$
\begin{aligned}
1+R^{k} & =(1+\Theta)(1+R) \\
\Theta & =\Theta\left(\frac{B}{N}\right)=\Theta\left(\frac{Q K}{N}-1\right) \\
Y & =A K^{\alpha} L^{1-\alpha}-F
\end{aligned}
$$

$$
\begin{aligned}
\frac{W L}{P_{H}^{W} Y} & =1-\alpha \\
\frac{Q\left(R^{k}+\delta\right) K}{P_{H}^{W} Y} & =\alpha
\end{aligned}
$$

$$
I=(g+\delta) K
$$$$
I=\left[\mathrm{w}_{I}^{1 / \rho_{I}} I_{H}^{\left(\rho_{I}-1\right) / \rho_{I}}+\left(1-\mathrm{w}_{I}\right)^{1 / \rho_{I}} I_{F}^{\left(\rho_{I}-1\right) / \rho_{I}}\right]^{\rho I /\left(1-\rho_{I}\right)}
$$

$$
\begin{aligned}
\frac{I_{H}}{I_{F}} & =\frac{\mathrm{w}_{I}}{1-\mathrm{w}_{I}}\left(\frac{P_{H}}{P_{F}}\right)^{-\rho_{I}} \\
P_{I} & =\left[\mathrm{w}_{I} P_{H}^{1-\rho_{I}}+\left(1-\mathrm{w}_{I}\right) P_{F}^{1-\rho_{I}}\right]^{1 /\left(1-\rho_{I}\right)}
\end{aligned}
$$

$$
Q \Phi^{\prime}\left(\frac{I}{K}\right)=\frac{P_{I}}{P}
$$

$$
P_{H}=\hat{P}_{H}=\frac{P_{H}^{W}}{1-(1 / \zeta)}
$$

$$
M C=\frac{P_{H}^{W}}{P_{H}}=1-\frac{1}{\zeta}
$$

$$
Y=C_{H}+\frac{1}{v}\left[C_{H}^{e}+C_{H}^{e *}+I_{H}+I_{H}^{*}\right]+\frac{1-v}{v} C_{H}^{*}+G
$$

$$
C_{H, t}^{e}=\left(1-\xi_{e}\right) V=\left(1-\xi_{e}\right)\left(1+R^{k}\right) N \equiv s_{e} C_{H, t}
$$

$$
T=G
$$

$U_{M_{H}}=U_{C} \frac{R_{n}}{1+R_{n}}$ 
(A27)

$$
U_{M_{F}}=U_{C} \frac{R_{n}^{*}}{1+R_{n}^{*}}
$$

plus the foreign counterparts. Note that (A28) ignores seigniorage arising in a zero inflation from growth. The steady steady is completed with

$$
\begin{aligned}
\mathcal{T} & =\frac{P_{F}}{P_{H}} \\
R E R & =\frac{S P^{*}}{P} \\
U_{C} & =U_{C}^{*} \frac{z_{0}}{R E R} .
\end{aligned}
$$

Units of output are chosen so that $P_{H}=P_{F}=1$. Hence, $\mathcal{T}=P=P_{I}=1$. Hence, with our assumptions regarding $\Phi(\cdot)$, we have that $Q=1$. We also normalize $S=1$ in the steady state so that $P_{F}^{*}=P_{H}^{*}=P^{*}=P_{I}^{*}=1$ as well. Then the steady state of the risk-sharing condition (A30) becomes $C=k C^{*}$, where $k$ is a constant.

\section{Appendix B}

\section{Linearization}

Exogenous Processes

$$
\begin{aligned}
a_{t+1} & =\rho_{\alpha} a_{t}+v_{a, t+1} \\
g_{t+1} & =\rho_{g} g_{t}+v_{g, t+1} \\
g_{t+1}^{*} & =\rho_{g}^{*} g_{t}^{*}+v_{g, t+1}^{*} \\
\varepsilon_{R, t+1}^{*} & =\rho_{R}^{*} \varepsilon_{R, t}^{*}+v_{R, t+1}^{*} \\
\varepsilon_{P, t+1} & =\rho_{P} \varepsilon_{P, t}+v_{P, t+1} \\
\varepsilon_{U I P, t+1} & =\rho_{U I P} \varepsilon_{U I P, t}+v_{U I P, t+1}
\end{aligned}
$$

Predetermined Variables

(B7) $k_{t+1}=\frac{1-\delta}{1+g} k_{t}+\frac{\delta+g}{1+g} i_{t}$ 
(B8) $k_{t+1}^{*}=\frac{1-\delta^{*}}{1+g} k_{t}^{*}+\frac{\delta^{*}+g}{1+g} i_{t}^{*}$

$$
n_{t}=\frac{\xi_{e}}{1+g}\left[\frac{1}{n_{k}} r_{t-1}^{k}+(1+\Theta)(1+R) n_{t-1}+\left(1-\frac{1}{n_{k}}\right)\right.
$$

$$
\left.\cdot\left[(1+R) \theta_{t-1}+(1+\Theta)\left(\varphi r_{t-1}\right)+(1-\varphi)\left(r_{t-1}^{*}\right)+(1+R)\left(r e r_{t}-\operatorname{rer}_{t-1}\right)\right]\right]
$$

$$
\begin{aligned}
n_{t}^{*}= & \frac{\xi_{e}^{*}}{1+g}\left[\frac{1}{n_{k}^{*}} r_{t-1}^{k *}+\left(1+\Theta^{*}\right)(1+R) n_{t-1}^{*}+\left(1-\frac{1}{n_{k}^{*}}\right)\right. \\
& \left.\cdot\left[(1+R) \theta_{t-1}^{*}+\left(1+\Theta^{*}\right) r_{t-1}^{*}\right]\right]
\end{aligned}
$$

where $r_{t-1}=r_{n, t-1}-\pi_{t}$ and $r_{t-1}^{*}=r_{n, t-1}^{*}-\pi_{t}^{*}$ are the ex post real interest rates.

$$
s_{t}=s_{t-1}+\operatorname{rer}_{t}-\operatorname{rer}_{t-1}+\pi_{t}-\pi_{t}^{*}
$$

Nonpredetermined Variables

(B12) $(1-\delta) E_{t}\left(q_{t+1}\right)=\left(1-R^{k}\right) q_{t}-\left(R^{k}+\delta\right) x_{t}+E_{t}\left(r_{t}^{k}\right)$

(B13) $\left(1-\delta^{*}\right) E_{t}\left(q_{t+1}^{*}\right)=\left(1+R^{k *}\right) q_{t}^{*}-\left(R^{k *}+\delta^{*}\right) x_{t}^{*}+E_{t}\left(r_{t}^{k *}\right)$

(B14)

$$
E_{t} u_{c, t+1}=u_{c, t}-\frac{r_{n, t}}{1+R}+E_{t} \pi_{t+1}
$$

$$
E_{t} u_{c, t+1}^{*}=u_{c, t}^{*}-\frac{r_{n, t}^{*}}{1+R}+E_{t} \pi_{t+1}^{*}
$$

(B17)

$$
\beta E_{t} \pi_{H, t+1}=\pi_{H, t}-\lambda_{H} m c_{t}
$$

(B18)

$$
\beta E_{t} \pi_{F, t+1}^{*}=\pi_{F, t}^{*}-\lambda_{F}^{*} m c_{t}^{*}
$$

$$
\left(1+\frac{1+g}{1+R}\right) i_{t}=\frac{1+g}{1+R} E_{t} i_{t+1}+i_{t-1}+\frac{1}{(1+g)^{2} S^{\prime \prime}(1+g)}\left(q_{t}-p_{I, t}+p_{t}\right)
$$

$$
\left(1+\frac{1+g}{1+R}\right) i_{t}^{*}=\frac{1+g}{1+R} E_{t} i_{t+1}^{*}+i_{t-1}^{*}+\frac{1}{(1+g)^{2} S^{\prime \prime}(1+g)}\left(q_{t}^{*}+p_{I, t}^{*}-p_{t}^{*}\right)
$$

Instrument

$$
r_{n, t}=\text { exogenous instrument }
$$

Outputs

(B21) $m c_{t}=u_{l, t}-u_{c, t}+l_{t}-\frac{1}{\phi_{F}} y_{t}+p_{t}-p_{H, t}$

(B22) $m c_{t}^{*}=u_{l, t}^{*}-u_{c, t}^{*}+l_{t}^{*}-\frac{1}{\phi_{F}^{*}} y_{t}^{*}+p_{t}^{*}-p_{F, t}^{*}$ 
(B23) $u_{c, t}=\frac{(1-\varrho)(1-\sigma)-1}{1-h_{C}}\left(c_{t}-h_{C} c_{t-1}\right)-\frac{L \varrho(1-\sigma)}{1-L} l_{t}$

$$
+\varpi\left[\bar{a} r_{n, t}+(1-\bar{a}) r_{n, t}^{*}\right]
$$

(B24)

$$
\begin{aligned}
u_{c, t}^{*}= & \frac{\left(1-\varrho^{*}\right)\left(1-\sigma^{*}\right)-1}{1-h_{C}^{*}}\left(c_{t}^{*}-h_{C}^{*} c_{t-1}^{*}\right)-\frac{L^{*} \varrho^{*}\left(1-\sigma^{*}\right)}{1-L^{*}} l_{t}^{*} \\
& +\varpi(1) r_{n, t}^{*}
\end{aligned}
$$

$$
u_{l, t}=\frac{1}{1-h_{C}}\left(c_{t}-h_{C} c_{t-1}\right)+\frac{L}{1-L} l_{t}+u_{c, t}+\left[\bar{a} r_{n, t}+(1-\bar{a}) r_{n, t}^{*}\right]
$$

$$
\begin{aligned}
& u_{t, t}^{*}=\frac{1}{1-h_{C}^{*}}\left(c_{t}^{*}-h_{C}^{*} c_{t-1}^{*}\right)+\frac{L^{*}}{1-L^{*}}\left(l_{t}^{*}-\varepsilon_{L, t}^{*}\right)+u_{c, t}^{*}+\varepsilon_{C, t}^{*}+\varpi_{L}^{*} r_{n, t}^{*} \\
& \text { (B27) } y_{t}=\alpha_{C, H} c_{t}+\alpha_{C, H}^{e} c_{t}^{e}+\alpha_{C, H}^{*} c_{t}^{*}+\alpha_{I, H} i_{t}+\alpha_{I, H}^{*} i_{t}^{*}+\alpha_{G} g_{t} \\
& +\left[\mu\left(\alpha_{C, H}+\alpha_{C, H}^{e}\right)(1-\mathrm{w})+\mu^{*} \alpha_{C, H}^{*} \mathrm{w}^{*}+\rho_{I} \alpha_{I, H}\left(1-\mathrm{w}_{I}\right)\right. \\
& \left.+\rho_{I}^{*} \alpha_{I, H}^{*} \mathrm{~W}_{I}^{*}\right] \tau_{t}
\end{aligned}
$$

(B28) $y_{t}^{*}=\alpha_{C, F}^{*} c_{t}^{*}+\alpha_{C, F}^{* e} c_{t}^{* e}+\alpha_{C, F} c_{t}+\alpha_{C, F}^{e} c_{t}^{e}+\alpha_{I, F}^{*} i_{t}^{*}+\alpha_{I, F} i_{t}+\alpha_{G}^{*} g_{t}^{*}$

$$
\begin{aligned}
& -\left[\mu^{*}\left(\alpha_{C, F}^{*}+\alpha_{C, F}^{* e}\right) c_{t}^{* e}\left(1-\mathrm{w}^{*}\right)+\mu \alpha_{C, F} \mathrm{~W}+\rho_{I}^{*} \alpha_{I, F}^{*}\left(1-\mathrm{w}_{I}^{*}\right)\right. \\
& \left.+\rho_{I} \alpha_{I, F} \mathrm{~W}_{I}\right] \tau_{t} \\
= & c_{y}^{*} c_{t}^{*}+i_{y}^{*} i_{t}^{*}+g_{y}^{*} g_{t}^{*} .
\end{aligned}
$$

(Note small open economy results: $\left.\mathrm{w}=\omega, \mathrm{w}_{I}=\omega_{I}, \mathrm{w}^{*}=\mathrm{w}_{I}^{*}=1.\right)$

$$
\begin{aligned}
c_{t}^{e}= & n_{t} \\
c_{t}^{e *}= & n_{t}^{*} \\
r e r_{t}^{r}= & u_{c, t}^{*}-u_{c, t} \\
\omega \tau_{t}= & r e r_{t} \\
\theta_{t}= & \chi_{\theta}\left(n_{t}-k_{t}-q_{t}\right)+\epsilon_{P, t} \\
\theta_{t}^{*}= & \chi_{\theta}^{*}\left(n_{t}^{*}-k_{t}^{*}-q_{t}^{*}\right)+\epsilon_{P, t}^{*} \\
E_{t}\left(r_{t}^{k}\right)= & (1+R) \theta_{t}+(1+\Theta)\left(\varphi E_{t}\left(r_{t}\right)\right. \\
& \left.+(1-\varphi) E_{t}\left(r_{t}^{*}\right)+(1+R)\left(E_{t}\left(r e r_{t+1}\right)-r e r_{t}\right)\right) \\
E_{t}\left(r_{t}^{k *}\right)= & (1+R) \theta_{t}^{*}+(1+\Theta *) E_{t}\left(r_{t}^{*}\right) \\
r_{t-1}^{k}= & (1-\delta) q_{t}-\left(1+R^{k}\right) q_{t-1}+\left(R^{k}+\delta\right) x_{t-1} \\
r_{t-1}^{k *}= & \left(1-\delta^{*}\right) q_{t}^{*}-\left(1+R^{k *}\right) q_{t-1}^{*}+\left(R^{k *}+\delta^{*}\right) x_{t-1}^{*} \\
E_{t}\left(r_{t}\right)= & r_{n, t}-E_{t}\left(\pi_{t+1}\right)
\end{aligned}
$$


(B40)

$$
\begin{aligned}
E_{t}\left(r_{t}^{*}\right) & =r_{n, t}^{*}-E_{t}\left(\pi_{t+1}^{*}\right) \\
p_{t}-p_{H, t} & =(1-\mathrm{w}) \tau_{t} \rightarrow(1-\omega) \tau_{t} \text { as } n \rightarrow 0 \\
\text { Note: } p_{t}^{*}-p_{F, t}^{*} & \left.=\left(1-\mathrm{w}^{*}\right) \tau^{*} \rightarrow 0\right) \\
p_{I, t}-p_{t} & =\left(\mathrm{w}-\mathrm{w}_{I}\right) \tau_{t} \rightarrow\left(\omega-\omega_{I}\right) \tau_{t}
\end{aligned}
$$

$\left(\right.$ Note: $\left.p_{I, t}^{*}-p_{t}^{*}=\left(1-\mathrm{w}_{I}^{*}\right) \tau_{t} \rightarrow 0\right)$

$$
\pi_{t}=\pi_{H, t}+(1-\omega) \Delta \tau_{t}
$$

$$
\pi_{t}^{*}=\pi_{F, t}^{*}
$$

$$
\pi_{F, t}=\pi_{H, t}+\Delta \tau_{t}
$$

$$
\pi_{H, t}^{*}=\pi_{F, t}^{*}-\Delta \tau_{t}
$$

$$
r f_{t}=\chi_{R}\left(r_{n, t}-r_{n, t}^{*}\right)
$$

$$
\begin{aligned}
(1-\alpha) l_{t} & =\frac{1}{\phi_{F}} y_{t}-a_{t}-\alpha k_{t} \\
(1-\alpha) l_{t}^{*} & =\frac{1}{\phi_{F}^{*}} y_{t}^{*}-a_{t}^{*}-\alpha k_{t}^{*} \\
x_{t} & =y_{t}+m c_{t}+p_{H, t}-p_{t}-k_{t} \\
x_{t}^{*} & =y_{t}^{*}+m c_{t}^{*}-k_{t}^{*} \\
E_{t} \pi_{t+1} & =\mathrm{w} E_{t} \pi_{H, t+1}+(1-\mathrm{w}) E_{t} \pi_{F, t+1} \\
E_{t} \pi_{F, t+1} & =E_{t} r e r_{t+1}-\operatorname{rer}+E_{t} \pi_{t+1}-E_{t} \pi_{t+1}^{*}+E_{t} \pi_{F, t+1}^{*} \\
E_{t} r e r_{t+1} & =E_{t} u_{c, t+1}^{*}-E_{t} u_{c, t+1}+E_{t}\left[\operatorname{rer}_{t+1}^{d}\right] \\
r_{n, t}^{*} & =\rho_{i}^{*} r_{n, t-1}^{*}+\left(1-\rho_{i}^{*}\right) \theta_{\pi}^{*} \pi_{F, t}^{*}+\varepsilon_{R, t}^{*} \\
q_{t}^{k} & =q_{t}-p_{I, t}+p_{t}
\end{aligned}
$$

(Note: $q_{t}^{k *}=q_{t}^{*}$ )

$$
\text { (Note: } X_{t} \equiv\left(P_{H, t} M C_{t} Y_{t}\right) /\left(P_{t} K_{t}\right) \text { in [B51].) }
$$

Foreign Asset Accumulation and Modified UIP

Linearizing around $B_{F}=T B=0$ we define

$$
\begin{aligned}
b_{F, t} & \equiv \frac{S_{t}\left(B_{F, t}+M_{F, t}\right)}{P_{H, t} Y_{t}} \\
t b_{t} & \equiv \frac{T B_{t}}{P_{H, t} Y_{t}} .
\end{aligned}
$$

Then we have in linearized form 


$$
\begin{aligned}
\beta b_{F, t}= & \frac{1}{1+g} b_{F, t-1}+t b_{t} \\
t b_{t}= & y_{t}-\alpha_{C, H} c_{t}-\alpha_{C, H}^{e} c_{t}^{e}-i_{y} i_{t}-g_{y} g_{t}-\left(c_{y}+i_{y}\right)\left(p_{t}-p_{H, t}\right) \\
& -i_{y}\left(p_{I, t}-p_{t}\right) .
\end{aligned}
$$

The real exchange rate is the risk-sharing value plus a risk premium deviation given by the system

$$
\begin{aligned}
r e r_{t} & =\operatorname{rer}_{t}^{r}+\operatorname{rer}_{t}^{d} \\
\operatorname{rer}_{t}^{r} & =u_{c, t}^{*}-u_{c, t} \\
E_{t}\left[\operatorname{rer}_{t+1}^{d}\right] & =\operatorname{rer}_{t}^{d}+\delta_{r} b_{F, t}+\varepsilon_{U I P, t} .
\end{aligned}
$$

\section{Appendix C}

\section{Calibration and Estimation}

We begin with estimates of the processes describing the exogenous shocks.

\section{Shock Parameters}

We require the AR1 persistence parameters $\rho_{a}, \rho_{g}, \rho_{g}^{*}, \rho_{r}^{*}, \rho_{P}, \rho_{U I P}$, and the corresponding standard deviations of white noise processes, $s d_{a}, s d_{g}$, and so forth. The following have been estimated by ordinary least squares (OLS).

Peru's TFP shock $\left(A_{t}\right)$ : AR coefficient: $0.59, \mathrm{SE}=1.1$ percent Peru's fiscal shock $\left(G_{t} / Y_{t}\right)$ : AR coefficient: $0.97, \mathrm{SE}=0.2$ percent U.S. fiscal shock $\left(G_{t} / Y_{t}\right)$ : AR coefficient: $0.78, \mathrm{SE}=0.8$ percent U.S. Taylor Rule:

$$
r_{n, t}^{*}=0.94 r_{n, t-1}^{*}+0.069 \pi_{F, t}^{*}+0.22\left(y_{t}^{*}-y_{t-1}^{*}\right)+\epsilon_{R, t}^{*} .
$$

$\operatorname{SE}\left(\epsilon_{R}\right)=0.36$ percent. Note that the long run of this rule satisfies the Taylor principle that the real interest rate should respond positively to an increase in inflation.

UIP shock: AR coefficient $=0.96, \mathrm{SE}=0.32$ percent

External finance premium shock: In the absence of any estimates in the literature this shock is calibrated to take central values for financial shocks: $\mathrm{AR}$ coefficient $=0.95, \mathrm{SE}=0.5$ percent .

\section{Preferences}

Risk Aversion Parameters: Estimates in the literature suggest the range $\sigma \in$ $[2,5]$. However, for the United States, Bayesian estimates suggest a range $\sigma^{*} \in[2,3]$. Our central estimates are $\sigma=3, \sigma^{*}=2$.

Discount Factors: A standard choice is $\beta=\beta^{*}=0.99$ 
Working Day: A standard value is $L^{*}=0.40$ for the United States. We choose a slightly higher value $L=0.5$ for Peru.

Habit Parameters: $h_{C}=0.7(\mathrm{CMT}), h_{C}^{*}=0.5$ (LOWW)

Substitution Elasticity: A standard choice for small open economies is $\mu=$ $\mu^{*}=1.5$.

Elasticity of the marginal utility of consumption with respect to money balances $\Psi, \Psi^{*}$ : We examine a range $\Psi, \Psi^{*} \in[0.01,0.03]$ for which money balances and consumption are complements.

Home currency consumption transactions: $a \in[0,1], \chi_{M}=4$. Estimated by CMT.

Technology

Depreciation Rates: A standard choice is $\delta=\delta^{*}=0.025$.

Common World Growth Rate: We choose a realistic common world growth rates: $g=g^{*}=3$ percent per annum.

Investment Adjustment Costs: We match Peru with European data using an estimate from SW, for United States we use LOWW obtaining $S^{\prime \prime}(1+g)$ $=6.0,\left[S^{\prime \prime}(1+g)\right]^{*}=4.0$ from SW.

Capital Shares: $\alpha=0.5$ (CMT), $\alpha^{*}=0.33(L O W W)$

Investment Substitution Elasticities: $\rho_{I}=\rho_{I}^{*}=0.25$

Financial Accelerator

Elasticity: $\chi_{\theta}=-0.065, \chi_{\theta}^{*}=-0.05$ (BGG)

Home currency borrowing for capital: $\varphi \in[0,1]$

Survival rate: $\xi_{e}=\xi_{e}^{*}=0.93(\mathrm{GGN})$

Asset/Debt Ratio: $n_{k}=0.4, n_{k}^{*}=0.7$ (BGG)

FA Risk Premium: $\Theta=0.035, \Theta *=0.05(\mathrm{BGG})$

UIP Risk Premium: $\delta_{r}=0.01$

Market Power

Labor Market Power: $\eta=3$ (SW), corresponding to a 50 percent markup, $\eta^{*}=6$, corresponding to a 20 percent markup.

Product Market Power: $\zeta=7.67$ corresponding to a 15 percent (SW, LOWW).

Pricing

Calvo Contract: A standard value $\xi_{H}=\xi_{F}^{*}=0.66$, corresponding to 3 quarter price contracts on average (see CMT).

Consumption, Investment, Money Balance, and Trade Shares

Standard values for the United States are $c_{y}^{*}=0.6, i_{y}^{*}=0.2, g_{y}=0.2$, and $z_{y}=0.25$ (the latter $z_{y}=Z / P Y$ is money stock as a proportion of quarterly GDP). For Peru we choose $c_{y}=0.7, i_{y}=0.15, g_{y}=0.1 .5$, and $z_{y}=0.25$ (as for the United States).

Trade Shares: Total exports and imports are around 25 percent for Peru so $0.25=c s_{\text {imports }}+i s_{\text {imports }}=c s_{\text {exports }}+i s_{\text {exports }}$ for balanced trade. Data 
on consumption and capital goods exports show $i s_{\text {imports }} / c s_{\text {imports }}=1.6$ and $i s_{\text {exports }} / c s_{\text {exports }}=0.1$. Hence, we choose $c s_{\text {imports }}=0.10$, $i s_{\text {imports }}=0.15$, $c s_{\text {exports }}=0.23$, and $i s_{\text {exports }}=0.02$.

\section{Derived Parameters}

Given these estimates and data observations, we can now calibrate the following parameters. Preference Parameters $(b, \theta, \varrho)$ are found by solving the set of equations

$$
\begin{aligned}
\frac{W(1-L)}{P C} & =\frac{(1-\alpha)(1-L)}{c_{y} L} \\
\Psi & =\frac{(1-b)[(1-\varrho)(1-\sigma)-1+(1 / \theta)}{b c z[(\theta-1) / \theta]+1-b} \\
\frac{\Phi}{C \Phi_{C}} & =\frac{(1-b) c z^{(1-\theta) / \theta}+b}{b} \\
c z & \equiv \frac{C\left(1-h_{C}\right)}{Z} \\
\varrho & =\frac{[1-(1 / \eta)] W(1-L) / P C}{\Phi /\left(C\left(1-h_{C}\right) \Phi_{C}\right)+[1-(1 / \eta)] W(1-L) / P C} \\
\frac{b\left(1-h_{C}\right)}{1-b} c z^{-1 / \theta} & =\frac{1+R}{R} .
\end{aligned}
$$

For central values of $\sigma$, assuming $\Psi=0.01$, we obtain: $b=0.95, \theta=0.28$, $\varrho=0.17$ for Peru data and $b^{*}=0.99, \theta=0.39$, and $\varrho=0.66$ for U.S. data.

Demand elasticities calibrated from trade data:

$$
\begin{aligned}
\alpha_{C, H} & =\left(c_{y}-c s_{\text {imports }}\right)\left(1-s_{e}\right) \\
\alpha_{C, H}^{e} & =\left(c_{y}-c s_{\text {imports }}\right) s_{e} \\
\alpha_{C, H}^{*} & =c s_{\text {exports }} \\
\alpha_{I, H} & =i_{y}-i s_{\text {imports }} \\
\alpha_{I, H}^{*} & =i s_{\text {exports }} \\
\alpha_{C, F}^{*} & =c_{y}^{*} \\
\alpha_{C, F}^{e *} & =0 \\
\alpha_{C, F} & =0 \\
\alpha_{I, F}^{*} & =i_{y}^{*} \\
\alpha_{I, F} & =0 \\
\alpha_{G} & =g_{y} \\
\alpha_{G}^{*} & =g_{y}^{*} .
\end{aligned}
$$


Note the small open economy implication that $\alpha_{C, F}=\alpha_{I, F}=0$. Then we have

$$
\begin{aligned}
\omega & =\frac{\alpha_{C, H}+\alpha_{C, H}^{e}}{c_{y}}=\frac{c_{y}-c s_{\text {imports }}}{c_{y}} \\
\omega_{I} & =\frac{\alpha_{I, H}}{i_{y}} .
\end{aligned}
$$

Remaining calibrated parameters are:

$$
\begin{aligned}
& g_{u_{\mathrm{c}}}=(1+g)^{(1-\varrho)(1-\sigma)-1}-1 \\
& R=\frac{1}{\beta\left(1+g_{u_{\mathrm{c}}}\right)}-1 \\
& R^{k}=(1+\Theta)(1+R)-1 \\
& \bar{a}=\bar{a}(a)=\frac{a^{\chi_{M}}}{a^{\chi_{M}}+(1-a)^{\chi_{M}}} \\
& \alpha=\left(a+a^{1-\chi}(1-a)^{\chi}\right)^{\theta /(\chi-1)}\left(\frac{(1-b) a}{b(1-\beta)}\right)^{\theta} \\
& =\left(\frac{(1-b)}{b(1-\beta)}\right)^{\theta} \text { for } a=1 \text { and } a \rightarrow 0 \\
& =\frac{1}{2^{\theta}}\left(\frac{(1-b)}{b(1-\beta)}\right)^{\theta} \text { for } a=\frac{1}{2} \\
& \alpha^{*}=\left(\frac{\left(1-b^{*}\right)}{b^{*}(1-\beta)}\right)\left(\text { Note: } a^{*}=1\right) \\
& b_{1}=b_{1}(a)=\frac{b}{\left(b+(1-b) \alpha^{(\theta-1) / \theta}\right)} \\
& \varpi=\varpi(a)=\frac{\beta}{1-\beta}[(1-(1-\varrho)(1-\sigma)) \theta-1]\left(1-b_{1}\right) \\
& \lambda_{H}=\frac{\left(1-\beta \xi_{H}\right)\left(1-\xi_{H}\right)}{\xi_{H}} \\
& \chi_{R}=\frac{\chi_{M}}{R_{n}\left(1+R_{n}\right)} \\
& k_{y}=\frac{i_{y}}{g+\delta} \\
& s_{e}=\frac{\left(1-\xi_{e}\right) n_{k} k_{y}}{\xi_{e} c_{y}} \\
& \varpi_{L}=\varpi_{L}(a)=\frac{\beta}{1-\beta}(1-\theta)\left(1-b_{1}\right) .
\end{aligned}
$$




\section{Appendix D}

\section{Proof of Propositions 1, 2 and Corollary 2}

Proposition 1. To study the FIX regime, we need to augment the system with a definitional equation relating the change in the nominal exchange rate to the change in the terms of trade and inflation. First, we assume that foreign prices are fixed, so in log terms $0=\Delta p_{F, t}^{*}=\Delta\left(p_{F, t}-s_{t}\right)=\Delta\left(p_{H, t}+\tau_{t}-s_{t}\right)$, where $\tau_{t}$ is the terms of trade in deviation form. Thus,

$$
s_{t}=s_{t-1}+\tau_{t}-\tau_{t-1}+\pi_{H t} .
$$

In addition, from the first-order conditions for consumption, we have a relationship between the real exchange rate and marginal utility of consumption $r e r_{t}=u_{c, t}^{*}-u_{c, t}$, and linearization of (10) yields $r e r_{t}=\omega \tau_{t}$. Hence,

$$
s_{t}=s_{t-1}-\frac{1}{\omega}\left[u_{c t}-u_{c, t-1}-\left(u_{c, t}^{*}-u_{c, t-1}^{*}\right)\right]+\pi_{H t} .
$$

Note that the implication of this equation is that feedback on the nominal exchange rate via (52) is a form of "integral control" (i.e., a sum of all past values) on inflation. It is known that integral control rules are very robust in terms of their stabilization properties.

Now put $r_{n, t}=r_{n, t}^{*}+\theta_{s} s_{t}$, as discussed previously; it is now easy to show that taken together with (62), this implies

$$
E_{t} s_{t+1}=\left(1+\theta_{s}\right) s_{t},
$$

from which we deduce that the nominal exchange rate is given by $s_{t}=0$ for all $t$. Note that this implies from (D2) that $u_{c, t}$ and $\pi_{H, t}$ are related under this feedback regime and therefore cannot "jump" independently of one another. Thus, we require that the part of the system that describes the joint behavior of these two variables must have one stable and one unstable eigenvalue. It is easy now to ascertain that their joint characteristic equation becomes

$$
(z-1)(\beta z-1)-\gamma \omega z=0,
$$

where $z$ is the forward operator. It is also easy to show that one root of this equation is greater than 1 , and the other lies between 0 and 1 . Hence, proposition 1 follows.

Proposition 2. Ignoring all exogenous and stochastic variables, yields a characteristic equation for (60), (65), and (62) given by

$$
(z-\rho)[(z-1)(\beta z-1)-\gamma \omega z]+(1-\rho) \theta_{\pi} z[\kappa(z-1)+\omega \gamma]=0 .
$$

The effects of dollarization can be assessed through the variation in $\kappa$, which is a function of $a$, where $1-a$ is the degree of dollarization. 
As pointed out in the previous section, the case of no dollarization is easily seen to be equivalent to that of a separable utility function. Indeed, for the case $\omega=1$, this is equivalent to the case of a closed economy. For the case of a partially dollarized economy, $\kappa>0$ is possible when consumption and real balances are complements, and it turns out that the results depend on the degree of dollarization.

For determinacy, since there are two jump variables, we require exactly two unstable roots. First note that when $\theta_{\pi}=0$, the eigenvalues of the system are given by $\rho$ and the roots of $(z-1)(\beta z-1)-\gamma \omega z$; it is easy to show that one of the latter roots is greater and the other is less than 1 , so the system is indeterminate. As $\theta_{\pi} \rightarrow \infty$, the roots tend to $-\infty$ and $1-\omega \gamma / \kappa$, so that the system has two unstable roots if $1-\omega \gamma / \kappa<-1$, as in (b), as required for determinacy, but only one unstable root for (b).

Equation (D.9) describes the root locus method that enables to track the path of the roots in the complex plane as $\theta_{\pi}$ changes. In this case, it is easy to show that the smaller of the two stable roots heads for $z=0$ as $\theta_{\pi}$ increases to $\infty$. Also, as $\theta_{\pi}$ increases to a value slightly beyond 1 , the other two roots move closer to one another. They merge into a double root at a value of $z>1$; to show this, we note that $z=1$ when $\theta_{\pi}=1$, so we need to prove that increasing $\theta_{\pi}$ beyond 1 leads to a root larger than 1 . It is trivial to show that this follows from the fact that

$$
\left.\frac{\partial z}{\partial \theta_{\pi}}\right|_{\theta_{\pi}=z=1}=\frac{\gamma \omega}{\gamma \omega+(1-\rho)(1-\beta-\kappa)} .
$$

This is greater than 0 for both (a) and (b). From this double root there are then two branches out into the complex plane, which merge for a much larger value of $\theta_{\pi}$ on to the negative part of the real axis, and then the roots diverge, one to $-\infty$, and the other to $1-\omega \gamma / \kappa$. Thus for case (b), there are two unstable roots for all $\theta_{\pi}$, provided that the root locus does not pass through the unit circle. Likewise for (a), if it does not pass through the unit circle, then there are two unstable roots for $1<\theta_{\pi}<\bar{\theta}_{\pi}$, where $\bar{\theta}_{\pi}$ is the value of $\theta_{\pi}$ such that there is a root at $z=-1$; there is an additional proviso, that the root locus passes through the point -1 from the left. But this follows from

$$
\left.\frac{\partial z}{\partial \theta_{\pi}}\right|_{z=-1}=\frac{(1-\rho)(2 \kappa-\gamma \omega)}{(1+\rho)(1-\beta)+(2(1+\beta)=\beta \omega)[\gamma \omega-(1-\rho) \kappa] /(2 \kappa-\gamma \omega)}
$$

which is also greater than 0 for case (b). Finally we need to show that when the root locus is off the real line, it does not cross the unit circle, which is characterized by $z=e^{i \psi}=\cos \psi+i \sin \psi$. To find a potential crossing, we substitute this into (D5) (with $\rho=0, j=0)$, then multiply by $e^{i \psi}$ and equate real and imaginary parts to 0 . These yield

$$
\begin{aligned}
0= & \beta \cos 2 \psi-(1+\beta+\omega \gamma+\rho+\rho \beta) \cos \psi+1 \\
& +\rho(1+\beta+\omega \gamma)+\theta_{\pi}(1-\rho)(\kappa \cos \psi+\omega \gamma-\kappa)
\end{aligned}
$$


(D9)

$$
0=\beta \sin 2 \psi-(1+\beta+\omega \gamma-\rho+\rho \beta) \sin \psi+\theta_{\pi}(1-\rho) \kappa \sin \psi
$$

There are obviously roots at $\sin \psi=0$, which corresponds to (i) $z=1, \theta_{\pi}=1$, which explains why we there is indeterminacy for $\theta_{\pi}<1$ (ii) $z=-1$, which only corresponds to positive $\theta_{\pi}$ for case (a). The alternative, after removing the factor $\sin \psi$ from (D9), is that $0=2 \beta \cos \psi-(1+\beta+\omega \gamma-\rho+\rho \beta)+\theta_{\pi}(1$ $-\rho) \kappa$. Substituting for $\cos \psi$ from this expression into (D8) yields a unique value of $\theta_{\pi}$. But for the locus to branch at a value of $z>1$, and return to the real line at a value of $z<-1$, it needs to cross the unit circle twice, but this is ruled out by this unique value of $\theta_{\pi} \cdot{ }^{27}$

COROLlary 2. First note that of all the parameters in (D5), only $\mathrm{\kappa}$ is dependent on dollarization, via the term $\bar{a}\left(1-b_{1}\right)$. The effect of increasing a on this term is given by

$$
\text { (D10) } \begin{aligned}
\frac{d\left(\bar{a}\left(1-b_{1}\right)\right)}{d a}= & \frac{\left.\chi_{M} B\left(a^{\chi_{M}}+(1-a)^{\chi_{M}}\right)^{(\theta-1) /\left(\chi_{M}-1\right)}\right)}{\left(a^{\chi_{M}}+(1-a)^{\chi_{M}}\right)^{2}\left(b+B\left(a^{\chi_{M}}+(1-a)^{\chi_{M}}\right)^{(\theta-1) /\left(\chi_{M}-1\right)}\right)^{2}} \\
& {\left[a ^ { \chi _ { M } - 1 } ( 1 - a ) ^ { \chi _ { M } - 1 } \left(b+B\left(a^{\chi_{M}}+(1-a)^{\left.\left.\chi_{M}\right)^{(\theta-1) /\left(\chi_{M}-1\right)}\right)}\right.\right.\right.} \\
& \left.+\frac{\theta-1}{\chi_{M}-1} b a^{\chi_{M}}\left(a^{\chi_{M}-1}-(1-a)^{\chi_{M}-1}\right)\right]
\end{aligned}
$$

where $B=(1-b)^{\theta} b^{1-\theta}(1-\beta)^{1-\theta}$.

Given that $\theta<1$, and in our calibrations we use $\chi_{M}>1$, it is easy to see that this is increasing for $a<1 / 2$. But dollarization is associated with decreasing $a$, which leads to a decrease in $\kappa$ as a decrease from $1 / 2$ to 0 . Thus, we have corollary 2 in the main text.

\section{Appendix $E$}

\section{Quadratic Approximation of the Welfare Loss}

The basic idea is to obtain the quadratic approximation to the social planner's problem, coupled with a term in inflation, which arises from price dispersion. We adopt a "small distortions" approximation, which is accurate as long as the zero inflation steady-state is close to the social optimum. As we have noted in the main text, the existence of external habit offsets the distortions in the product and labor markets. For our calibrated high value for the 
habit parameter $h_{C}$, this leaves the steady state of the decentralized economy close to the social optimum, justifying the small distortions approximation.

Consider the social planner's problem to maximize

$$
\sum_{t=0}^{\infty} \beta^{t} \frac{\left(C_{t}-h_{C} C_{t-1}\right)^{(1-\varrho)(1-\sigma)}\left(1-L_{t}\right)^{\varrho(1-\sigma)}}{1-\sigma},
$$

subject to the (resource) constraints:

(E2) $1-\omega+\omega T_{t}^{\mu-1}=E_{t}^{\mu-1} \quad 1-\omega_{I}+\omega_{I} T_{t}^{\rho_{I}-1}=E_{I t}^{\mathrm{g} I-1} \quad K_{t}=(1-\delta) K_{t-1}+I_{t}$

$$
\begin{aligned}
Y_{t}+\Phi=A_{t} K_{t-1}^{\alpha} L_{t}^{1-\alpha}= & \omega E_{t}^{-\mu} T_{t}^{\mu} C_{t}+\left(1-\omega^{*}\right) T_{t}^{\mu} C_{t}^{*}+\omega_{I} E_{I t}^{-\rho_{I}} T_{t}^{\rho_{I}} I_{t} \\
& +\left(1-\omega_{I}^{*}\right) T_{t}^{\rho_{I}^{*}} I_{t}^{*}+G_{t}
\end{aligned}
$$

where the terms of trade are given by $T=P_{F} / P_{H}$, and the real exchange rate as $E=S P^{*} / P$, so that $E^{1-\mu}=P_{F}^{1-\mu}\left[\omega P_{H}^{1-\mu}+(1-\omega) P_{F}^{1-\mu}\right]$. There is a risk-sharing condition given by

$$
E_{t}=\frac{U_{C_{t}^{*}}^{*}}{U_{C_{t}}} \quad E_{t} C_{t}^{(1-\varrho)(1-\sigma)-1}\left(1-L_{t}\right)^{\varrho(1-\sigma)}=C_{t}^{*(1-\varrho)(1-\sigma)-1}\left(1-L_{t}^{*}\right)^{\varrho(1-\sigma)}
$$

where we assume initial wealth per capita is the same in each country.

The Lagrangian for the problem may be written as

$$
\begin{aligned}
\sum_{t=0}^{\infty} \beta^{t}[ & \frac{\left(C_{t}-Z_{t}\right)^{(1-\varrho)(1-\sigma)}\left(1-L_{t}\right)^{\varrho(1-\sigma)}}{1-\sigma}+\lambda_{1 t}\left(Z_{t}-h_{C} C_{t-1}\right) \\
& +\lambda_{2 t}\left(\omega E_{t}^{-\mu} T_{t}^{\mu} C_{t}+\left(1-\omega^{*}\right) T_{t}^{\mu} C_{t}^{*}+\omega_{I} E_{I t}^{-\rho_{I}} T_{t}^{\rho_{I} I_{t}}\right. \\
& \left.+\left(1-\omega_{I}^{*}\right) T_{t}^{\rho_{I}^{*}} I_{t}^{*}+G_{t}-A_{t} K_{t-1}^{\alpha} L_{t}^{1-\alpha}\right)+\lambda_{3 t}(1-\omega \\
& \left.+\omega T_{t}^{\mu-1}-E_{t}^{\mu-1}\right)+\lambda_{4 t}\left(1-\omega_{I}+\omega_{I} T_{t}^{\rho_{I}-1}-E_{I t}^{\rho_{I}-1}\right) \\
& +\lambda_{5 t}\left(E_{t} C_{t}^{(1-\varrho)(1-\sigma)-1}\left(1-L_{t}\right)^{\varrho(1-\sigma)}-U_{C^{*}}\right) \\
& \left.+\lambda_{6 t}\left(K_{t}-(1-\delta) K_{t-1}-I_{t}\right)\right] .
\end{aligned}
$$

First-order conditions with respect to $C, Z, E, T, E_{I}, I, L$, and $K$ yield

$$
\begin{aligned}
0= & (1-\varrho)(C-Z)^{(1-\varrho)(1-\sigma)-1}(1-L)^{\varrho(1-\sigma)}-\beta \lambda_{1} h_{C}+\lambda_{2} \omega E^{-\mu} T^{\mu} \\
& +\lambda_{5}[(1-\sigma)(1-\varrho)-1] E(C-Z)^{(1-\varrho)(1-\sigma)-1}(1-L)^{\varrho(1-\sigma)} \\
0= & -(1-\varrho)(C-Z)^{(1-\varrho)(1-\sigma)-1}(1-L)^{\varrho(1-\sigma)}+\lambda_{1} \\
& +\lambda_{5}[(1-\sigma)(1-\varrho)-1] E(C-Z)^{(1-\varrho)(1-\sigma)-1}(1-L)^{\varrho(1-\sigma)} \\
0= & -\lambda_{2} \mu \omega E^{-\mu-1} T^{\mu} C-\lambda_{3}(\mu-1) E^{\mu-2}+\lambda_{5}(C-Z)^{(1-\varrho)(1-\sigma)-1} \\
& \cdot(1-L)^{\varrho(1-\sigma)} \\
0= & \lambda_{2} T^{\mu-1}\left(\omega E^{-\mu} C+(1-\omega) C^{*}\right)+\lambda_{2} \rho_{I} T^{\rho^{I}-1}\left(\omega_{I} E_{I}^{-\rho_{I} I}+\left(1-\omega_{I}\right) I^{*}\right. \\
& +\lambda_{3} \omega(\mu-1) T^{\mu-2}+\lambda_{4} \omega_{I}\left(\rho_{I}-1\right) T^{\rho^{\prime}-2}
\end{aligned}
$$


(E10) $0=-\lambda_{2} \rho_{I} \omega_{I} E_{I}^{-\rho_{I}-1} T^{\rho_{I} I}-\lambda_{4}\left(\rho_{I}-1\right) E_{I}^{\rho_{I}}$

(E11) $0=\lambda_{2} \omega_{I} E_{I}^{-\rho_{I}} T_{\rho_{\mathrm{I}}}-\lambda_{6}$

(E12) $0=-\varrho(C-Z)^{(1-\varrho)(1-\sigma)}(1-L)^{\varrho(1-\sigma)-1}-\lambda_{2} A(1-\alpha) K^{\alpha} L^{-\alpha}$ $-\lambda_{5} \varrho(1-\sigma) E(C-Z)^{(1-\varrho)(1-\sigma)-1}(1-L)^{\varrho(1-\sigma)-1}$

(E13) $0=\lambda_{2} \alpha A K^{\alpha-1} L^{1-\alpha}+\lambda_{6}\left(\frac{1}{\beta}-1+\delta\right)$.

In steady state these satisfy

(E14) $\quad \alpha A\left(\frac{L}{K}\right)^{1-\alpha}=\omega_{I}\left(\frac{1}{\beta}-1+\delta\right)=\omega_{I} R_{K} \quad \lambda_{4}\left(1-\rho_{I}\right)=\lambda_{2} \rho_{I} \omega_{I} I$

(E15) $\quad \lambda_{3} \omega(1-\mu)=\lambda_{2}\left(\mu_{C}+\rho_{I}\left(1-\omega_{I}^{2}\right) I\right) \quad\left(1-\beta h_{C}\right) \lambda_{1}=-\omega \lambda_{2}$

$$
\lambda_{5} F=-\frac{\lambda_{2}}{\omega}\left[\mu\left(1-\omega^{2}\right) C+\rho_{I}\left(1-\omega_{I}^{2}\right) I\right]
$$

where

$$
F=\left(C\left(1-h_{C}\right)\right)^{(1-\varrho)(1-\sigma)-1}(1-L)^{\varrho(1-\sigma)} .
$$

Also define

$$
F_{1}=\left(C\left(1-h_{C}\right)\right)^{(1-\varrho)(1-\sigma)}(1-L)^{\varrho(1-\sigma)}=C\left(1-h_{C}\right) F .
$$

It can be shown that the second-order expansion is given by the sum of the following terms

$$
\begin{aligned}
& \frac{F_{1}}{2}\left(\frac{(1-\varrho)[(1-\sigma)(1-\varrho)-1]\left(c_{t}-h_{C} c_{t-1}\right)^{2}}{\left(1-h_{C}\right)^{2}}\right. \\
& \left.\quad-2 \frac{(1-\sigma)(1-\varrho) \varrho L\left(c_{t}-h_{C} c_{t-1}\right) l t}{\left(1-h_{C}\right)(1-L)}+\frac{\varrho[(1-\sigma) \varrho-1] L^{2} l_{t}^{2}}{(1-L)^{2}}\right)
\end{aligned}
$$

(which is negative definite)

$$
\begin{aligned}
& \text { (E20) }\left(\frac{\lambda_{2} \mathrm{C} \mu}{2}\left[2 \omega^{3}-3 \omega+1+\mu \omega(1-\omega)^{2}\right]\right. \\
&+\frac{\lambda_{2} I \rho_{I}}{2}\left[\left(1-\omega_{I}\right)^{2}(\mu \omega-3 \omega-\mu)+1-\omega_{I}^{3}+\rho_{I}\left(1-3 \omega_{I}^{2}+2 \omega_{I}^{3}\right]\right) \tau_{t}^{2} \\
& \text { (E21) } \frac{\lambda_{2} A \alpha(1-\alpha) K^{\alpha} L^{1-\alpha}}{2}\left(k_{t-1}-l_{t}\right)^{2}-\lambda_{2} A K^{\alpha} L^{1-\alpha}\left[(1-\alpha) l_{t}+\alpha k_{t-1}\right] a_{t}
\end{aligned}
$$

(E22) $\lambda_{2}\left(\mu \omega(1-\omega) C c_{t}+\mu\left(1-\omega^{*}\right) C c_{t}^{*}\right.$

$$
\left.+\rho_{I} \omega_{I}\left(1-\omega_{I}\right) I i_{t}+\rho_{I}^{*}\left(1-\omega_{I}^{*}\right) I i_{t}^{*}\right) \tau_{t}
$$


(E23)

$$
\begin{aligned}
& \lambda_{2}\left(\mu\left(1-\omega^{2}\right) C+\rho_{I}\left(1-\omega^{2}\right) I\right) \\
& \quad \cdot\left([(1-\sigma)(1-\varrho)-1] \frac{c_{t}^{*}-h_{C} c_{t-1}^{*}}{1-h_{C}}-(1-\sigma) \varrho \frac{L^{*} l_{t}^{*}}{1-L^{*}}\right) \tau_{t} .
\end{aligned}
$$

Price dispersion arising from price setting behavior by firms yields a second-order term

$$
-\frac{\varrho L F_{1}}{2(1-L)} \frac{\zeta \xi_{H}}{\left(1-\xi_{H}\right)\left(1-\beta \xi_{H}\right)} \pi_{t}^{2} .
$$

Finally, we require an expression for $\lambda_{2}$, which is obtained from

$$
\begin{array}{r}
\lambda_{2}\left(A(1-\alpha)\left(\frac{K}{L}\right)^{\alpha}+\frac{\varrho(1-\sigma)}{\omega(1-L)}\left[\mu\left(\omega^{2}-1\right) C+\rho_{I}\left(\omega_{I}^{2}-1\right) I\right]\right)= \\
-\frac{\varrho C\left(1-h_{C}\right) F}{1-L} .
\end{array}
$$

If $\sigma>1$, it follows that $\lambda_{2}<0$. Note, too, that we may write

$$
-\frac{\varrho c_{y}\left(1-h_{C}\right) F}{\left[(1-\alpha) R_{K} \omega_{I} k_{y} / \alpha\right][(1-L) / L]+[\varrho(1-\sigma) / \omega]\left[\mu\left(\omega^{2}-1\right) c_{y}+\rho_{I}\left(\omega_{I}^{2}-1\right) i_{y}\right]} .
$$

Finally we can divide all terms by $\mathrm{FY}$, and by writing $F_{1}=F Y\left(1-h_{C}\right) c_{y}$, we can obtain all weights in terms of ratios $c_{y}, i_{y}, k_{y},(1-L) / L$, and parameters.

Note that there is an issue here of which values $C, L$ we use in all of these expressions. There is an additional representation of $\lambda_{2}$ for the social planner's problem, which leads ultimately to a linear relationship between $C$ and $L$, and then via the goods market equation to a complete expression for each of these. One can go through this procedure, or just use the steadystate values of observed ratios $C / Y, I / Y$, and $G / Y$. We choose to do the latter.

To obtain the quadratic form, define

$$
\begin{aligned}
c m c l_{t}= & \frac{c_{t}-h_{C} c_{t-1}}{1-h_{C}} \\
k m l_{t}= & k_{t-1}-l_{t} \\
c c i i_{t}= & \mu \omega(1-\omega) c_{y} c_{t}+\mu\left(1-\omega^{*}\right) c_{y} c_{t}^{*}+\rho_{I} \omega_{I}\left(1-\omega_{I}\right) i_{y} i_{t} \\
& +\rho_{I}^{*}\left(1-\omega_{I}^{*}\right) i_{y} i_{t}^{*}
\end{aligned}
$$

$$
\operatorname{ccsls}_{t}=[(1-\sigma)(1-\varrho)-1] \frac{c_{t}^{*}-h_{C} c_{t-1}^{*}}{1-h_{C}}-(1-\sigma) \varrho \frac{L^{*} l_{t}^{*}}{1-L^{*}} .
$$

And define

(E31) $\lambda=\frac{\varrho c_{y}\left(1-h_{C}\right)}{\left[(1-\alpha) R_{K} \omega_{I} k_{y} / \alpha\right][(1-L) / L]+[\varrho(1-\sigma) / \omega]\left[\mu\left(\omega^{2}-1\right) c_{y}+\rho_{I}\left(\omega_{I}^{2}-1\right) i_{y}\right]}$. 
Converting the welfare approximation into welfare loss, and dividing by $F Y$ leads to

$$
\begin{aligned}
2 W= & -\left(1-h_{C}\right) c_{y}\left((1-\varrho)[(1-\sigma)(1-\varrho)-1] c m c l_{t}^{2}\right. \\
& \left.-2(1-\sigma) \varrho(1-\varrho) c m c l_{t} \frac{L l_{t}}{1-L}+\frac{\varrho[(1-\sigma) \varrho-1] L^{2} l_{t}^{2}}{(1-L)^{2}}\right) \\
& -\left(\lambda c_{y} \mu\left[2 \omega^{3}-3 \omega+1+\mu \omega(1-\omega)^{2}\right]+\frac{\lambda i_{y} \rho_{I}}{2}\right. \\
& \left.\cdot\left[\left(1-\omega_{I}\right)^{2}(\mu \omega-3 \omega-\mu)+1-\omega_{I}^{3}+\rho_{I}\left(1-3 \omega_{I}^{2}+2 \omega_{I}^{3}\right)\right]\right) \tau_{t}^{2} \\
& -\lambda \frac{\Phi+Y}{Y} \alpha(1-\alpha) k m l_{t}^{2}+2 \lambda \frac{\Phi+Y}{Y} y_{t} a_{t}-2 \lambda c c i i_{t} \tau_{t} \\
& -2 \lambda c c s s_{t} \tau_{t}+\frac{\varrho L\left(1-h_{C}\right)}{(1-L)} \frac{\zeta \xi_{H}}{\left(1-\xi_{H}\right)\left(1-\beta \xi_{H}\right)} \pi_{t}^{2},
\end{aligned}
$$

which corresponds to (57) in the main text.

The change in welfare for a small change in consumption-equivalent over all periods is given by

$$
\text { (E33) } \begin{aligned}
\Delta \Omega & =(1-\rho) \sum_{t=0}^{\infty} \beta^{t} C\left(1-h_{C}\right)^{(1-\sigma)(1-\rho)-1}(1-L)^{\rho(1-\sigma)}\left(\Delta C-h_{C} \Delta C\right) \\
& =\frac{(1-\rho)\left(1-h_{C}\right) c_{y}}{1-\beta} F Y c_{e} .
\end{aligned}
$$

Ignoring the term in $F Y=C\left(1-h_{C}\right)^{(1-\sigma)(1-\rho)-1}(1-L)^{\rho(1-\sigma)} Y$, since all the welfare loss terms have been normalized by this, we can rewrite this as

$$
c_{e}=\frac{(1-\beta) \Delta \Omega}{(1-\rho)\left(1-h_{C}\right) c_{y}} .
$$

Furthermore, if all welfare loss terms have been further normalized by $(1-\beta)$, and that all variances are expressed in percent ${ }^{2}$, it follows that we can write $c_{e}$ in percent terms as

$$
c_{e}=\frac{\Delta \Omega}{(1-\rho)\left(1-h_{C}\right) c_{y}} \times 10^{-2},
$$

which corresponds to (61) in the main text.

\section{References}

Adam, K., and R. M. Billi. 2007. Discretionary monetary policy and the zero lower bound on nominal interest rates. Journal of Monetary Economics 54 (3): 728-52.

Aoki, K., and T. Kimura. 2007. Uncertainty about perceived inflation target and monetary policy. Paper presented at the Bundesbank-Federal Reserve Bank of 
Cleveland Conference Monetary Policy: Old and New Challenges. 6-7 June, Frankfurt am Main.

Barro, R., and X. Sala-i-Martin. 2004. Economic growth, 2nd ed. New York: McGraw-Hill.

Batini, N., P. Breuer, and K. Kochhar. 2006. Inflation targeting and the IMF. International Monetary Fund Board Paper. Washington, DC: IMF.

Batini, N., R. Harrison, and S. Millard. 2003. Monetary policy rules for open economies. Journal of Economic Dynamics and Control 27 (11-12): 2059-94.

Batini, N., P. Levine, and J. Pearlman. 2004. Indeterminancy with inflation-forecastbased rules in a two-bloc model. European Central Bank (ECB) Discussion Paper no. 340 and Federal Reserve Board (FRB) Discussion Paper no. 797, presented at the International Research Forum on Monetary Policy. 14-15 November, Washington, DC.

Benigno, P. 2001. Price stability with imperfect financial integration. CEPR Discussion Paper no. 2854.

Benigno, G., and P. Benigno. 2004. Exchange rate determination under interest rate rules. Revised version of Center for Economic Policy Research (CEPR) Discussion Paper no. 2807, 2001.

Bernanke, B., M. Gertler, and S. Gilchrist. 1999. The financial accelerator in quantitative business cycles. In Handbook of macroeconomics, vol. 1C, ed. M. Woodford and J. B. Taylor, Amsterdam: Elsevier Science.

Calvo, G., and F. Mishkin. 2003. The mirage of exchange rate regimes for emerging market countries. Journal of Economic Perspectives 17 (4): 99-118.

Castillo, P., C. Montoro, and V. Tuesta. 2006. An estimated stochastic general equilibrium model with partial dollarization: A Bayesian approach. Central Bank of Chile Working Paper no. 381.

Cespedes, L. F., R. Chang, and A. Velasco. 2004. Balance sheets and exchange rate policy. American Economic Review 94 (4): 1183-93.

Coenen, G., and V. Wieland. 2003. The zero-interest rate bound and the role of the exchange rate for monetary policy in Japan. Journal of Monetary Economics 50 (5): 1071-1101.

Eggertsson, G. 2006. The deflation bias and committing to being irresponsible. Journal of Money, Credit and Banking 36 (2): 283-322.

Eggertsson, G., and M. Woodford. 2003. The zero interest-rate bound and optimal monetary policy. Brooking Papers on Economic Activity 1: 139-211. Washington, DC: Brookings Institution.

Felices, G., and V. Tuesta. 2006. Monetary policy in a partially dollarized economy. Mimeo.

Gertler, M., S. Gilchrist, and F. M. Natalucci. 2003. External constraints on monetary policy and the financial accelerator. NBER Working Paper no. 10128. Cambridge, MA: National Bureau of Economic Research, December.

Gesell, S. 1934. The natural economic order. Trans. Philip Pye. San Antonio, TX: Free-Economy Publishing.

Gilchrist, S. 2003. Financial markets and financial leverage in a two-country wordEconomy. Central Bank of Chile Working Paper no. 228.

Gilchrist, S., J.-O. Hairault, and H. Kempf. 2002. Monetary policy and the financial accelerator in a monetary union. European Central Bank Working Paper no. 175.

International Monetary Fund. 2005. Does inflation targeting work in emerging markets? In World economic outlook, chapter 4. Washington, DC: IMF, fall.

Keynes, J. M. 1936. The general theory of employment, interest and money. New York: Macmillan.

Levin, A., A. Onatski, J. C. Williams, and N. Williams. 2006. Monetary policy under 
uncertainty in micro-founded macroeconomic models. In NBER Macroeconomics Annual, 2005, ed. M. Gertler and K. Rogoff, 229-387. Cambridge, MA: MIT Press.

Levine, P., P. McAdam, and J. Pearlman. 2007. Quantifying and sustaining welfare gains from monetary commitment. ECB Working Paper no. 709. Presented at the 12th International Conference on Computing in Economics and Finance. June, Cyprus.

Levine, P., J. Pearlman, and R. Pierse. 2006. Linear-quadratic approximation, efficiency and target-implementability. Paper presented at the 12th International Conference on Computing in Economics and Finance. June, Cyprus.

Levy Yeyati, E. 2006. Financial dollarization: Evaluating the consequences. Economic Policy 21 (45): 61-118.

Obstfeld, M., and K. Rogoff. 1995. Exchange rate dynamics redux. Journal of Political Economy 103 (3): 624-60.

Primiceri, G. 2006. Comment on "Monetary policy under uncertainty in microfounded macroeconomic models." In NBER macroeconomics annual, 2005, ed. M. Gertler and K. Rogoff, 289-296. Cambridge, MA: MIT Press.

Ravenna, F., and C. E. Walsh. 2006. Optimal monetary policy with the cost channel. Journal of Monetary Economics 53 (2): 199-216.

Smets, F., and R. Wouters. 2003. An estimated Stochastic Dynamic General Equilibrium Model of the euro area. Journal of the European Economic Association 1 (5): 1123-75.

Woodford, M. 2003. Foundations of a theory of monetary policy. Princeton, NJ: Princeton University Press.

\section{Comment Frederic S. Mishkin}

There are several key features of emerging market economies that make them very different from advanced economies: they have weak fiscal, monetary policy, and financial institutional frameworks that lead to high levels of transactions and liabilities denominated in foreign currencies (dollarization) and larger credit market imperfections. ${ }^{1}$ The chapter by Batini, Levine, and Pearlman is very nice because, given the special features of emerging market economies, it asks exactly the right questions in examining macroeconomic policy issues in these economies: (a) How do financial frictions affect macroeconomic volatility and monetary policy? (b) Because of extensive dollarization, should the exchange rate have a special role in monetary policy?

In my discussion of the chapter, I will first discuss what it does, as well as

Frederic S. Mishkin is the Alfred Lerner Professor of Banking and Financial Institutions, Graduate School of Business, Columbia University, and a research associate of the National Bureau of Economic Research.

For presentation at the NBER conference on International Dimensions of Monetary Policy S'Agaró, Catalonia, Spain, June 12, 2007. The views expressed in this chapter are exclusively those of the author and do not necessarily reflect those of Columbia University, the National Bureau of Economic Research, the Board of Governors, or the Federal Reserve System.

1. For example, see Calvo and Mishkin (2003) and Mishkin (2006). 